NBER WORKING PAPER SERIES

FERTILITY DECLINE IN THE CIVIL RIGHTS ERA

Owen Thompson

Working Paper 26047

http://www.nber.org/papers/w26047

NATIONAL BUREAU OF ECONOMIC RESEARCH
1050 Massachusetts Avenue
Cambridge, MA 02138
July 2019

I thank seminar participants at the Minnesota Population Center, the Upjohn Institute for Employment Research, the University of Massachusetts and Williams College for helpful comments. Portions of the Vital Statistics data used in this study were transcribed and generously made available under NIA grant P30-AG012810. The views expressed herein are those of the author and do not necessarily reflect the views of the National Bureau of Economic Research.

NBER working papers are circulated for discussion and comment purposes. They have not been peer-reviewed or been subject to the review by the NBER Board of Directors that accompanies official NBER publications.

(C) 2019 by Owen Thompson. All rights reserved. Short sections of text, not to exceed two paragraphs, may be quoted without explicit permission provided that full credit, including () notice, is given to the source. 
Fertility Decline in the Civil Rights Era

Owen Thompson

NBER Working Paper No. 26047

July 2019

JEL No. J13,J71,J78

\begin{abstract}
$\underline{\text { ABSTRACT }}$
Large black-white fertility differences are a key feature of US demography, and are closely related to the broader dynamics of US racial inequality. To better understand the origins and determinants of racial fertility differentials, this paper examines fertility patterns in the period surrounding passage and implementation of the 1964 Civil Rights Act, which precipitated a period of rapid socioeconomic and political progress among African Americans, with these gains strongly concentrated in the South. I first show that the relative fertility of southern black women precipitously declined immediately after 1964. Specifically, as of 1964 the general fertility rate of southern black women was 53 births greater than the general fertility rate of southern white women, but by 1969 this gap had fallen to 33 births, a decline of approximately $40 \%$ in five years. The black-white fertility gap outside of the South was unchanged over this period. Measures of completed childbearing similarly show rapid black-white fertility convergence in the South but not in the North. An analysis of potential mechanisms finds that a substantial share of the observed fertility convergence can be explained by relative improvements in the earnings of southern blacks, and that the historical intensity of slavery and lynching activity are the strongest spacial correlates of fertility convergence
\end{abstract}

Owen Thompson

Department of Economics

Williams College

24 Hopkins Hall Drive

Williamstown, MA 01267

and NBER

ot3@williams.edu 


\section{Introduction}

Large black-white differences in fertility are among the most salient and persistent demographic features of the United States. As early as the 1830 Census, the completed childbearing of African American women was observed to be more than one full child greater than that of white women, and large black-white fertility differentials were maintained through emancipation, industrialization, the baby boom, and the advent of effective reproductive control methods, among other transformative fertility-related events (Tolnay 1981; Tamura et al. 2016; Bailey \& Hershbein 2018).

Black-white fertility differences are in part a consequence of discrimination faced by African Americans. For example, discriminatory labor markets will reduce the opportunity cost of children by lowering the potential earnings of black parents, and unequal access to educational and medical services will constrain the ability of African American parents to invest heavily in the human capital of a smaller number of children (see Becker 1960). More fundamentally, for extended periods of US history African American women have had minimal protections against sexual violence or other violations of reproductive autonomy (Roberts 1999).

In addition to being a result of discrimination, racial fertility differences have also likely been one cause of the contemporary persistence of racial inequality. For example research indicates that fertility events have large and sustained negative impacts on women's labor supply and wages (Angrist \& Evans 1998; Kleven et al. 2019), such that greater fertility among African American women will depress their total earnings relative to groups with lower fertility. Similarly, there is evidence that larger family sizes and higher birth orders have negative effects on children's educational and labor market outcomes (Black et al. 2005; Conley \& Glauber 2006; Sacerdote 2007), and racial fertility differentials will mechanically cause the average African American child to come from a larger family and be of a higher birth order than the average white child.

Given these strong and multidirectional relationships between fertility and socioeconomic outcomes, understanding the nature and causes of racial differences in fertility is critical for understanding the nature and causes of US racial inequality more generally.

Recent work has used historical events to better understand the origins and determinants of racial fertility differentials. For example, Allen (2015) studies the fertility outcomes of enslaved women before and after implementation of the Fugitive Slave Act, and finds that fertility declined with the probability of successful escape. Likewise, Aaronson et al. (2014) examines the fertility of African American women around the introduction of the Rosenwald schools in the early 20th century. The authors find that women whose children gained greater educational access due to these schools reduced their total fertility but were also more likely to have at least one child, while women whose own access to education was improved decreased their fertility on both the intensive and extensive margin.

The current paper examines changes in race-specific fertility patterns around another key historical event, passage and implementation of the 1964 Civil Rights Act. This act was the legislative culmination of the decades long Civil Rights Movement, and precipitated a period of rapid progress among African Americans across a wide variety of economic, social and political dimensions.

Two features of the Civil Rights Act make it a particularly informative context for studying race-specific fertility determination. First, its provisions had direct and qualitatively large impacts on numerous fertility determinants, for instance labor market opportunity and access to education and health services. Second, its provisions were typically effective immediately after 1964 and were by far the most binding for southern 
blacks, with much less consequential effects for northern blacks or whites in any region (Donohue \& Heckman 1991; Wright 2013). These features naturally suggest a transparent research design in which changes in fertility among southern black women before and after 1964 are compared with fertility changes among other race-by-region groups over the same period.

The first section of the paper implements such a design to document a novel set of descriptive facts about the relative fertility outcomes of southern black women in the Civil Rights Era. In particular, I show that there was a qualitatively large and discontinuous decline in the general fertility rates of southern African American women immediately after 1964, with no comparable decline among northern black women or white women in any region. Completed fertility measures similarly show large-scale reductions in the average number of children ever born among southern black women, which was driven by substitution out of very high levels of completed fertility. I then assess various mechanisms that may have contributed to this rapid fertility convergence by performing decompositions and by analyzing geographic heterogeneity in the strength of relative black fertility decline.

\section{Post-1964 Fertility Convergence}

I begin by simply reporting trends in the general fertility rate (GFR) from 1955-1975, disaggregated by race and region. ${ }^{1}$ Following convention, I calculate the GFR as the ratio of total live births to the number of women between ages 14 and 44, measured in thousands. Live birth totals by state are drawn from Vital Statistics print reports from 1955-1967 and from digitized Vital Statistics microdata from 1968-1975. Population counts by gender, age and race are drawn from the Decennial Census with linear interpolations for 1955-1968, and from the Survey of Epidemiology and End Results (SEER) for 1969-1975.

Figure 1A plots the level GFR trends from 1955 through 1975. The figure shows that among southern black women fertility rates fall substantially after 1964, with the average number of births per thousand southern black women of childbearing age declining from 151 in 1964 to 118 in 1969. The other race-by-region groups also experienced declining fertility rates over this period, but the magnitudes of these reductions are smaller and none display a discrete post-1964 trend break comparable to southern black women, implying that there was a strong convergence in the fertility rates of southern blacks and the other groups after 1964 .

The precipitous and discontinuous nature of this post-1964 convergence is seen more clearly in Figure 1B, which plots black-white fertility differences by region. The solid line in Figure 1B shows that in 1964 there were 53 more live births per thousand women of childbearing age among southern blacks than there were among southern whites, but by 1969 this gap had fallen to 33 births, a decline of approximately $40 \%$ over a five year period. The dashed line in Figure 1B plots black-white fertility rate differences outside of the South, and finds no relative decline in the fertility rates of African American women after 1964.

Figure 1 effectively used southern whites, northern blacks, and northern whites as control groups that accounted for any fertility determinants that were general to all women from a given region or racial group. A conceptually similar alternative is to pool all regions and races, then estimate regressions that include

\footnotetext{
${ }^{1}$ I define the South as the eleven states of the Former Confederacy, with the remaining lower 48 states constituting the North, and in Appendix A I demonstrate that the results are not sensitive to alternative regional definitions, and also report results on a state-by-state basis. Maternal race is aggregated only into white and non-white, but blacks were the dominant minority population in this context, and in Appendix A I show that the results are not sensitive to excluding counties where African Americans constituted less than $99 \%$ of the non-white population.
} 
three-way interactions between year dummies, a black dummy, and a South dummy. I report results of such a "triple-difference" specification in Appendix A, and the results similarly demonstrate large relative fertility declines among southern black women immediately after 1964. Appendix A also demonstrates that this result holds when the GFR is entered in logs, so that fertility changes can be interpreted in percentage terms.

Figure 2 reproduces Figure 1B, but disaggregates by five-year maternal age groupings using data from print Vital Statistics books transcribed by the author. The figure shows that large-scale and unique reductions in the black-white GFR gap occurred after 1964 among southern women in all age groups except 15-19.

Figures 1 and 2 reported fertility rates, which are distinct from the total number of children born over the full course of a woman's childbearing years, or completed fertility. Fortunately the Decennial Censuses of 1970, 1980 and 1990 asked all female respondents ages 14 and over the total number of children ever born to them, and I use responses to this question among Census respondents ages 44-70 to measure completed childbearing across cohorts of women whose fertile-aged years spanned $1964 .^{2}$

The use of completed fertility measures from the Census offers two additional advantages. First, Census respondents report both state of birth and state of residence, rather than solely state of residence as in the Vital Statistics data, which is a potentially important distinction given the large-scale and heavily selected inter-regional migration that occurred among African Americans during the 20th century. Here I simply exclude inter-regional migrants from the analysis, and in Appendix B I demonstrate that the findings are robust to defining southern status on the basis of either current region of residence or region of birth, and also report fertility trends specifically for migrants. Second, completed fertility measures contain information on the full fertility distribution, which allows me to assess which parity margins drove overall fertility reductions.

Figure 3A displays trends in the black-white completed fertility differential for the 1920-1946 birth cohorts, disaggregated by region. For reference, dashed vertical lines indicate the 1929 and 1944 birth cohorts, which is the range of cohorts that were ages $20-35$ as of 1964 and whose prime childbearing years therefore spanned 1964. The solid line shows that as of the 1929 birth cohort, the completed fertility of southern black women was approximately 1.5 live births greater on average than the completed fertility of southern white women, but that by the 1944 birth cohort this difference had fallen to approximately .8 live births, a reduction of approximately $50 \%$ in the span of 15 birth cohorts. No similar reduction is observed outside of the South. Appendix B reports the results of "triple-difference" regression specifications that include three-way interactions between cohort dummies, a black dummy, and a South dummy, which similarly demonstrate large reductions in the completed fertility of southern black women relative to other race-by-region groups.

I note that the cohort trends shown in Figure 3A do not directly implicate events occurring in 1964, and are instead plausibly consistent with a much broader set of factors affecting the cohorts of the 1930s and early 1940s. However, the annual fertility rates shown in Figures 1 and 2 clearly indicate a strong period effect centered specifically around 1964, in which southern black women of virtually all ages (and thus various cohorts) discretely reduced their fertility at this particular point in time. Such a period effect being observed specifically for southern black women strongly implicates Civil Rights related explanations for relative fertility declines, and would not have been evident using only cohort-based measures such as Figure 3A. This highlights the importance of analyzing time, age and cohort level trends to fully understand

\footnotetext{
${ }^{2}$ Censuses prior to 1970 only asked this question of ever-married women and the question was dropped entirely after 1990 , which only allows completed fertility to be observed through the 1946 cohort. In Appendix B I use CPS June Fertility Supplements to examine a wider range of cohorts, and find similar patterns.
} 
changing fertility behavior in this context.

Figure 3B extends the analysis beyond simple means by showing histograms of the race-specific completed fertility distribution among southern women who were born between 1925 and 1930 (prior the convergence shown in Figure 3A) versus those who were born between 1941-1946 (after the convergence shown in Figure $3 \mathrm{~A})$. For southern black women, the figure indicates a dramatic truncation of the right-tail of the completed fertility distribution between these two sets of cohorts, with large numbers of women substituting out of completed fertility levels in the range of 6-12 children ever born and into fertility levels in the range of 1-4 children ever born. In contrast, changes in the completed fertility of southern white women were much less drastic during this period, and consisted primarily of substituting from completed fertility levels of 3-4 children ever born and into completed fertility of 2-3 children ever born. Consistent with Aaronson et al. (2014), the figure also shows relative increases in the portion of southern black women having at least one child, which may reflect the fact that one cannot invest in child "quality" without having at least one child.

The remainder of the paper explores the mechanisms potentially underlying the documented fertility trends.

\section{Explaining Fertility Convergence}

\subsection{Theoretical Framework}

To help structure the analysis of mechanisms, I adopt the theoretical framework of Galor (2012), who considers a household that maximizes a utility function $U(c, q, w)$ by choosing non-child consumption $(c)$, the quantity of children (q), and the well-being of each child $(w)$ or child "quality." Households are subject to the budget constraint $q\left(\tau^{q}+\tau^{w} w\right)+c \leq I$, where $\tau^{q}$ denotes the fixed-costs of each child, $\tau^{w}$ denotes the price of child well-being, and $I$ is normalized household income. At an interior optimum of $\left(q^{*}, w^{*}\right)$, the shadow price of child quantity and child well-being are respectively given by:

$$
\begin{gathered}
P_{q}=\tau^{q}+\tau^{w} w^{*} \quad \text { and } \\
P_{w}=\tau^{w} q^{*} .
\end{gathered}
$$

These equations show that the shadow price of child quantity is increasing in child well-being, while the shadow price of child well-being is increasing in child quantity. Fertility transitions occur when these relationships induce self-reinforcing substitution of child well-being for child quantity. Other than arbitrarily assuming changes in preferences, the key parameters that may change to engender a fertility transition are the fixed costs of each child $\left(\tau^{q}\right)$ and the price of generating child well-being $\left(\tau^{w}\right)$. For present purposes, the central question is how these parameters changed among southern blacks after 1964.

The most important changes in the fixed costs of children $\left(\tau^{q}\right)$ likely took the form of increased opportunity costs from forgone labor market earnings. In particular, to the extent that Civil Rights Act implementation reduced labor market discrimination and increased the potential earnings of southern African Americans, the relative fixed costs of children would increase among southern blacks after $1964 .{ }^{3}$ A closely related

\footnotetext{
${ }^{3}$ Since children are typically assumed to be a normal good, increased income could also have a positive effect on child quantity. The fact that fertility declined with potential earnings in the current context suggests that any income effect is dominated by substitution into child well-being.
} 
consideration is that many southern blacks left agricultural employment during the study period, often transitioning to positions in recently desegregated textile mills and other urban employers (Wright 2013). To the extent that child labor is more prevalent in rural agriculture than wage labor markets in metropolitan areas, urbanization would also increase the net fixed costs of children.

With respect to changes in the price of child well-being $\left(\tau^{w}\right)$, events such as the desegregation of southern schools and medical facilities would have directly reduced $\tau^{w}$ among southern blacks by decreasing barriers to investing in children's human capital development and increasing the efficacy of such investments. A related channel through which $\tau^{w}$ may have fallen among southern blacks is an increase in the anticipated future returns to human capital, such that any investment in child human capital would be more readily translated into desirable socioeconomic outcomes. If the parameter $\tau^{w}$ is interpreted broadly as the price of generating favorable child outcomes, rather than narrowly as the price of human capital inputs, then anticipated future reductions in discrimination would also lower the price of child well-being and cause relative fertility reductions among southern blacks.

There were also a large number of plausibly relevant federal policy shifts and changes in social norms during the study period. For instance War on Poverty programs such as Medicaid, Head Start and the Food Stamp Program directly reduced barriers to investing in children's health and education; The introduction of Enovid for contraceptive purposes in 1960, the initiation of the federal Family Planning Program in 1964, and the national legalization of abortion in 1973 would all have decreased the costs associated with preventing a birth; And gender norms in both the family and the workplace were rapidly changing in this period, with substantial overall decreases in marriage rates and increases in female labor force participation (Goldin 2006). An ex-ante reason to be skeptical of these factors as explanations for the trends documented above is that they typically applied to all racial groups and all regions, whereas the documented fertility decline is distinct to southern African Americans. But to the extent that southern blacks were especially impacted by these changes, they may have contributed to the documented convergence.

\subsection{Decompositions in Census Microdata}

Empirically, there are two necessary conditions for any proposed mechanism to have plausibly contributed to the fertility patterns found above. First, the proposed mechanism must have changed differentially among southern blacks after 1964. Second, the proposed mechanism must be associated with fertility. For example an increase in real or potential earnings is one potential mechanism suggested by the theoretical framework. In order for earnings to indeed be a valid mechanism, it is necessary both that the relative earnings of southern blacks actually improved after 1964, and also that there is a negative relationship between earnings and fertility. This reasoning suggests that one potentially insightful approach to empirically assessing a proposed mechanism is to estimate (1) the extent to which the proposed mechanism changed differentially among southern blacks after 1964 and (2) the strength of the proposed mechanism's association with fertility.

While intuitive and transparent, such an approach requires data with information on both fertility outcomes and relevant individual and household characteristics. The Vital Statistics data used above had the advantages of being measured annually and containing the near-universe of live births, but was aggregated to the state or county level and did not contain detailed information on the characteristics of mothers or families. Fortunately, the studied fertility decline occurred between the Decennial Censuses of 1960 and 1970, which makes it possible to observe large cross-sections of women shorty before and shortly after 1964 in a data set 
that also contains demographic and socioeconomic measures.

An important limitation of Census data is that respondents were not directly asked their recent fertility histories. To overcome this limitation, I measure fertility rates by restricting the 1960 and 1970 Census samples to females ages 14-44 and observing whether household rosters indicate that these women were living with an own-child under the age of one. If such a child is present, I assume that the woman experienced a live birth in the past year.

This approach to measuring fertility within household surveys is commonly used by demographers (see Palmore \& Gardner 1983), but will underestimate the true fertility rate in cases where children die before their first birthday or do not live with their biological mothers, and will overestimate the true fertility rate in cases where step-children, adopted children or other relationship types are misidentified as own-children. In Appendix C I compare this fertility rate measure to the corresponding measures in the Vital Statistics data, both with and without infant mortality adjustments. I find that the fertility rates implied by the household structure of Census respondents are overall moderately lower than those from Vital Statistics records, but that Census-based estimates of GFR changes from 1960-1970 are very similar to those in Vital Statistics data, suggesting that this approach to measuring fertility is reasonably reliable for present purposes.

Using this data, I formalize the intuition discussed above regarding the necessary conditions for particular characteristics to be contributing mechanisms by implementing a variant of the decomposition method proposed by Gelbach (2016). As described in more detail momentarily, this decomposition is based on the common technique of adding control variables to a baseline regression specification and observing the extent to which the coefficient on a variable of interest is attenuated. While this decomposition approach is systematic, I note at the outset that it is primarily descriptive in nature. It effectively calculates the change in fertility that would have been expected given the changes in a set of observable characteristics and the associations between those characteristics and fertility. But standard concerns related to omitted variables, reverse causality, and other sources of bias prevent the associations between observable characteristics and fertility from being interpreted causally. Despite this limitation, a systematic accounting of how fertility correlates changed for southern blacks and whites over the study period remains valuable for assessing potential mechanisms.

The first step of the decomposition estimates the changes in potentially relevant characteristics occurring between 1960 and 1970. The analyzed characteristics were chosen to proxy for the theoretical mechanisms discussed above, and include individual and family level earnings, urban and rural residence, labor force participation, educational attainment, and marital status, as well as age at the time of the survey. To estimate the group-specific changes in these characteristics occurring between 1960 and 1970, I simply regress each characteristic onto a 1970 indicator separately for southern black women and southern white women. The results are reported in Columns 1 and 2 of Table 1, with each row reporting changes in a separate characteristics. $^{4}$

With respect to earnings, the results in Table 1 indicate that between 1960 and 1970 the individual and family level earnings of southern black women increased by $\$ 7,626$ and $\$ 21,700$, respectively (in constant year 2000 dollars). Among southern white women, the analogous changes were only $\$ 4,389$ and $\$ 14,895$, indicating substantial relative economic progress among southern black women in this period. These relative

\footnotetext{
${ }^{4}$ Here I focus on changes in the fertility rates of southern black women relative to southern white women, and also exclude women born in one region but residing in the other. In Appendix C I report results that incorporate women in the North as additional control observations, as well as results that include inter-regional migrants.
} 
gains make income a highly plausible contributing mechanism for the documented fertility convergence.

Table 1 also finds that the fraction of southern black women residing in rural (non-metropolitan) areas fell by 9.4 percentage points between 1960 and 1970, but that southern white women also experienced an 8.4 percentage point decline in rural residence. This relatively small difference in rural residence declines will likely limit the magnitude of urbanization's role in fertility convergence. ${ }^{5}$ Likewise, Table 1 finds that the labor force participation rate of southern black women increased by 4.2 percentage points between 1960 and 1970, but increased by an even greater 7.9 percentage points among southern white women over the same time period. This likely reflects the relatively high baseline labor force participation rate of African American women (see Boustan \& Collins 2014), and makes labor force participation an unlikely explanation for fertility convergence.

Turning to educational attainment, Table 1 shows that high school graduation rates increased substantially more among southern black women than southern white women in this period, but that increases in college attendance and completion were stronger for southern white women, making the potential fertility impacts of changes in educational attainment ambiguous.

Finally, marriage rates fell for both racial groups in this period, but these marriage declines were stronger for southern black women (8.4 percentage points) than for southern white women (5.2 percentage points). Southern black women were also more likely to remain never-married, whereas southern white women experienced increases in being divorced, separated or widowed (the omitted category). As discussed below, the stronger reduction in marriage rates among southern blacks may have been a cause of fertility decline, but was equally plausibly an effect of fertility decline, complicating the assessment of marriage as a potential mechanism.

The next step of the decomposition estimates changes in the fertility rates of southern black women and southern white women between 1960 and 1970, first unconditionally and then conditional on the set of studied covariates:

$$
\begin{aligned}
& I\left(\text { Child }_{<1}\right)_{i} \times 1000=\beta Y 1970_{i}+\varepsilon_{i} \\
& I\left(\text { Child }_{<1}\right)_{i} \times 1000=\beta Y 1970_{i}+X_{i} \gamma+\varepsilon_{i} .
\end{aligned}
$$

In these models $I(\text { Child }<1)_{i}$ is an indicator of whether woman $i$ was living with an own-child under the age of one (multiplied by 1,000 to match standard GFR units), $Y 1970_{i}$ is an indicator of whether woman $i$ was observed in the 1970 Census rather than the 1960 Census, and $X_{i}$ is the vector of covariates.

Focusing first on the unconditional models, reported in Columns 3 and 5 of Table 1, the GFR of southern black women is estimated to have fallen by 38.3 births per thousand women of childbearing age between 1960 and 1970, while the GFR of southern white women is estimated to have fallen by 25.2 over the same period. These coefficients imply that the difference in the GFRs of southern blacks and southern whites converged by $38.3-25.2=13.1$ births between 1960 and 1970, an estimate that is generally consistent with the 17.8 birth convergence shown in Figure 1, which was derived using a wholly separate data source and methodology.

\footnotetext{
${ }^{5}$ The omitted residence category is suburban, so that the reported coefficients imply that southern black women primarily moved from rural to urban areas, while southern white women primarily moved from rural to suburban areas.
} 
Turning to the conditional models, reported in Columns 4 and 6 of Table 1, adding the full set of controls causes the estimated fertility reduction occurring between 1960 and 1970 among southern black women to fall from 38.3 to 20.7 , while the estimated fertility reduction occurring among southern white women over the same period falls from 25.2 to 21.5 . The change in the black-white fertility gap between 1960 and 1970 conditional on the included covariates is therefore $20.7-21.5=-0.8$ births per thousand women of childbearing age, which indicates that the entirety of the black-white fertility convergence occurring between 1960 and 1970 can be descriptively "explained" by the included set of controls.

With respect to the coefficients on the covariates themselves, income and urban residence have the expected negative correlations with fertility, especially within the southern black sample. ${ }^{6}$ Similarly, being in the labor force, being single, and being older all have strong negative associations with fertility. Finally, women with greater educational attainment actually have higher fertility rates in this context, conditional on the other covariates.

While the results in Columns 3-6 of Table 1 indicate that convergence can be fully attributed to the utilized set of controls as a whole, they do not readily indicate which of the included covariates account for the observed reduction. One common practice is to sequentially add covariates and observe the corresponding reduction in the independent variable of interest, but such reductions will often depend on the arbitrary order in which covariates are added. As an alternative, Gelbach (2016) shows that the contribution of each individual covariate will be equal to the product of the change in that covariate occurring between 1960 and 1970 (as reported in Columns 1 and 2) and the covariate's coefficient in the model with the full control vector (as reported in Columns 4 and 6). Gelbach (2016) also shows that the estimated contribution of each covariate under this method will sum to the total reduction from adding the full set of controls as an identity, that it is valid to sum these products over groups of covariates, and that because the conditional effect of each covariate is used, the results do not depend on the arbitrary choice of which covariates are added first.

The results of a decomposition using this approach are reported in Column 7 of Table $1 .^{7}$ The results indicate that relative changes in earned income were an important contributor to the documented black-white fertility convergence. Specifically Column 7 finds that individual and family level earnings jointly "explain" a 4.9 birth reduction in the black-white fertility gap among southern women, or $35 \%$ of the total observed reduction of 13.1 births. Changes in rural versus urban residence account for an additional 1.1 birth decline in the black-white fertility gap, or approximately $8 \%$ of the total unconditional convergence. These contributions are jointly due to the strong association of fertility with income and rural residence, even conditional on the other covariates, and to the presence of relative changes in these characteristics among southern black women between 1960 and 1970.

In contrast, the decomposition finds that relative changes in female labor force participation rates would have been expected to actually increase the black-white GFR gap by 3.1 births between 1960 and 1970, which is due to the relatively large increases in labor force participation rates among southern white women and the strongly negative conditional association between labor force participation and fertility. Educational attainment and age explain small and statistically insignificant portions of fertility convergence, primarily

\footnotetext{
${ }^{6}$ Note that because separate models are estimated for southern black women and southern white women, the coefficients on the covariates are not restricted to be equal across racial groups.

${ }^{7}$ The mechanical calculation of the results reported in Column 7 is as follows: Each covariate's coefficient in the fully specified models (Columns 4 and 6) is multiplied by its level change between 1960 and 1970 (Columns 1 and 2), and the value of this product among southern white women is subtracted from the analogous product among southern black women. The contributions of related covariates are then summed. Standard errors are calculated using the formulas derived by Gelbach (2016), and clustered at the state level.
} 
because black-white differences in these characteristics did not change in a uniform fashion between 1960 and 1970 .

Changes in marital status have by far the most explanatory power among the included covariates, accounting for an 11.4 birth reduction in the black-white GFR gap between 1960 and 1970. As noted, the decomposition exercise is descriptive in nature, and cannot identify whether the strong association between marriage and fertility is due to reductions in marriage causing lower fertility, lower fertility causing reductions in marriage, or some combination of the two. Additionally, there is no evidence that marriage rates discontinuously fell among southern blacks in 1964, and the declines observed in Table 1 are instead part of longer-term secular reductions in marriage. Given these considerations, it is arguably preferable to exclude marital status from the decomposition, and such results are reported in Appendix C. With marriage excluded, the overall explanatory power of the covariate vector unsurprisingly falls substantially, but the estimated impacts of the other covariates are very similar to those reported in Table 1. In particular, changes in income and urban residence continue to exert significant negative influences on black-white fertility gaps, while changes in labor force participation typically work in the opposite direction.

Appendix $\mathrm{C}$ also reports various robustness checks and extensions of the decomposition from Table 1 , for instance using various alternative covariate vectors, not excluding inter-regional migrants, and including women in the North as additional controls. These analyses find that while the overall explanatory power of the covariates and the values of some parameters often do vary substantially across specifications, the estimated contributions of income and urbanization are highly robust and similar to those shown in Table 1.

In summary, decompositions suggest that basic socioeconomic characteristics, most importantly earnings, robustly explain a substantial portion of the observed black-white fertility convergence. This is due to the simple observation that earnings have a strong theoretical and empirical relationship with fertility and that the earnings growth of southern blacks between 1960 and 1970 was unusually large. However, changes in observable socioeconomic characteristics do not provide a comprehensive explanation for southern black fertility decline, necessitating the examination of additional potential mechanisms.

\subsection{Geographic Heterogeneity}

A limitation of the utilized decomposition approach was that many of the potential mechanisms suggested by the theoretical framework are not readily observable. For instance Census respondents do not report the segregation status of their local schools and hospitals or their participation in federal programs, and factors like the extent to which the Civil Rights Act led to an updating of the anticipated level of discrimination that black parents believed their children would face are even more nebulously defined and difficult to quantify. In the absence of direct measures, it may be insightful to analyze heterogeneity in the strength of fertility convergence across smaller geographic areas, with counties being the smallest areas with race-specific fertility data available.

Interpreting any spacial variation in fertility patterns faces several limitations. In addition to standard omitted variable and selection bias concerns, non-random migration is a much more acute issue at the county level than at the regional level. This is both because cross-county migration is simply more common than cross-region migration, and because many of the mechanisms that may have caused relative fertility declines, for instance urbanization, virtually necessitate migration. This makes it difficult to distinguish between 
changes in fertility behavior within a county's existing population versus changes in the composition of its population.

These issues notwithstanding, it is still potentially insightful to systematically examine geographic patterns in the intensity of post-1964 fertility convergence, and Figure 4 maps the changes in the black-white fertility gap occurring between 1964 and 1969 across the 712 southern counties with available data. ${ }^{8}$ Figure 4 shows substantial spacial heterogeneity in the magnitude of post-CRA racial fertility convergence, with the strongest convergence occurring in counties along the Mississippi River Delta, selected counties in central Alabama and Georgia, and counties in the tobacco-growing regions of Virginia and North Carolina.

A natural question is how the characteristics of counties with stronger post-1964 convergence differed from those with more modest convergence magnitudes. In Appendix D I assemble a detailed county-level data set with measures of school and hospital desegregation and the presence of Head Start, Medicaid, the Food Stamp Program and the Family Planning Program. I also assemble data on the antebellum density of enslaved African Americans and the prevalence of lynchings from 1882-1930, which existing literatures have shown to be strong proxies for the intensity of discriminatory institutions, racial violence, and racially conservative political attitudes (Bertocchi \& Dimico 2013; Acharya et al. 2016; Cook et al. 2018). As such, I expect the changes engendered by the Civil Rights Act to be more binding and impactful in areas with higher historic levels of enslavement and lynching.

The analyses in Appendix D find substantive positive associations between the local magnitude of relative black fertility declines and the intensity of local school desegregation, hospital access, and War on Poverty programs. However, a county's historical intensity of slavery and lynching activity are the strongest and most robust spacial correlates of post-CRA fertility convergence by a substantial margin. I interpret this finding as suggestive evidence that the social and psychological ramifications of dismantling of the most overt forms of state-sponsored racism significantly contributed to the documented decline in black-white fertility differences in the Civil Rights period.

\section{Conclusion}

Large black-white fertility differences are a key feature of US demography, and are closely related to broader dynamics of racial inequality. This paper showed that the racial fertility gap in the South fell precipitously and discontinuously after 1964, suggesting that the fertility behavior of African American women was highly responsive to changes in discriminatory institutions in this historical context.

\footnotetext{
${ }^{8} \mathrm{~A}$ majority of counties with missing data in Figure 4 are due to race-specific natality data being unavailable in counties where non-whites constituted less than $10 \%$ of the population. Additionally, because the natality data classifies race only as white or non-white, the figure excludes 37 counties where more than $1 \%$ of the population in the 1970 census consisted of non-black minorities, which ensures that non-whites consist almost exclusively of African Americans.
} 


\section{References}

Aaronson, D., Lange, F., \& Mazumder, B. (2014). Fertility transitions along the extensive and intensive margins. American Economic Review, 104(11), 3701-3724.

Acharya, A., Blackwell, M., \& Sen, M. (2016). The political legacy of American slavery. Journal of Politics, 78(3), 621-641.

Allen, T. (2015). The promise of freedom: Fertility decisions and the escape from slavery. Review of Economics and Statistics, 97(2), 472-484.

Angrist, J. \& Evans, W. (1998). Children and their parents' labor supply: Evidence from exogenous variation in family size. American Economic Review, 88(3), 450-477.

Bailey, M. \& Hershbein, B. (2018). US fertility rates and childbearing, 1800-2010. Oxford Handbook of American Economic History.

Becker, G. (1960). An economic analysis of fertility. In Demographic and economic change in developed countries, 209-240. Columbia University Press.

Bertocchi, G. \& Dimico, A. (2014). Slavery, education, and inequality. European Economic Review, 70, 197-209.

Black, S., Devereux, P. \& Salvanes, K. (2005). The more the merrier? The effect of family size and birth order on children's education. Quarterly Journal of Economics, 120(2), 669-700.

Boustan, L. \& Collins, W. (2014). The origin and persistence of black-white differences in women's labor force participation. In Human capital in history: The American Record, University of Chicago Press.

Conley, D. \& Glauber, R. (2006). Parental educational investment and children's academic risk estimates of the impact of sibship size and birth order from exogenous variation in fertility. Journal of Human Resources, 41(4), $722-737$.

Cook, L., Logan, T. \& Parman, J. (2018). Racial segregation and southern lynching. Social Science History, 42(4), 635-675.

Donohue III, J. \& Heckman, J. (1991). Continuous versus episodic change: The impact of civil rights policy on the economic status of blacks. Journal of Economic Literature, 29(4), 1603-1643.

Galor, O. (2012). The demographic transition: causes and consequences. Cliometrica, 6(1), 1-28.

Gelbach, J. (2016). When do covariates matter? And which ones, and how much? Journal of Labor Economics, 34(2), 509-543.

Goldin, C. (2006). The quiet revolution that transformed women's employment, education, and family. American Economic Review, 96(2), 1-21.

Kleven, H., Landais, C., Posch, J., Steinhauer, A. \& Zweimüller, J. (2019). Child penalties across countries: Evidence and explanations. NBER Working Paper.

Palmore, J. \& Gardner, R. (1983). Measuring mortality, fertility, and natural increase: A self-teaching guide to elementary measures. East-West Population Institute.

Roberts, D. (1999). Killing the black body: Race, reproduction, and the meaning of liberty. Vintage Books. 
Sacerdote, B. (2007). How large are the effects from changes in family environment? A study of Korean American adoptees. Quarterly Journal of Economics, 122(1), 119-157.

Tamura, R., Simon, C. \& Murphy, K. (2016). Black and white fertility, differential baby booms: The value of equal education opportunity. Journal of Demographic Economics, 82(1), 27-109.

Tolnay, S. (1981). Trends in total and marital fertility for black Americans, 1886-1899. Demography, 18(4), 443-463.

Wright, G. (2013). Sharing the prize. Harvard University Press. 


\section{Figure 1: Fertility Rates by Year, Race and Region}
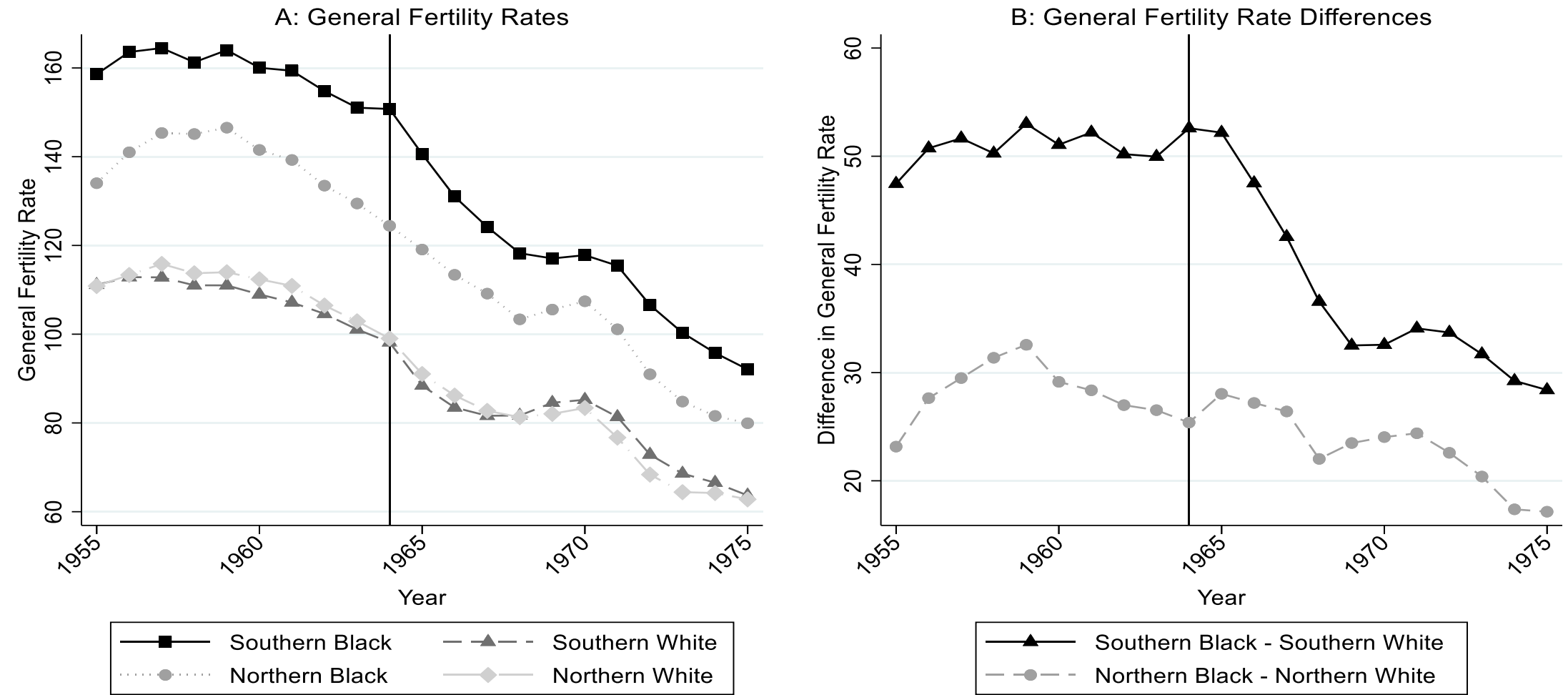

Notes: Panel A shows trends in the General Fertility Rate (GFR), which is calculated as the ratio of total live births to the population of females ages 1444, expressed in thousands. Panel B shows the simple differences in the GFRs from Panel A between the specified groups. Live birth totals are drawn from Vital Statistics print reports from 1955-1967 and from Vital Statistics microdata from 1968-1975. Population counts by gender, age and race are drawn from the Decennial Census with linear interpolations for 1955-1968, and from the Survey of Epidemiology and End Results (SEER) for 1969-1975. The South consists of Alabama, Arkansas, Florida, Georgia, Louisiana, Mississippi, North Carolina, South Carolina, Tennessee, Texas and Virginia, and the North consists of the balance of the lower 48 states. 


\section{Figure 2: Age-Specific General Fertility Rate Differences}
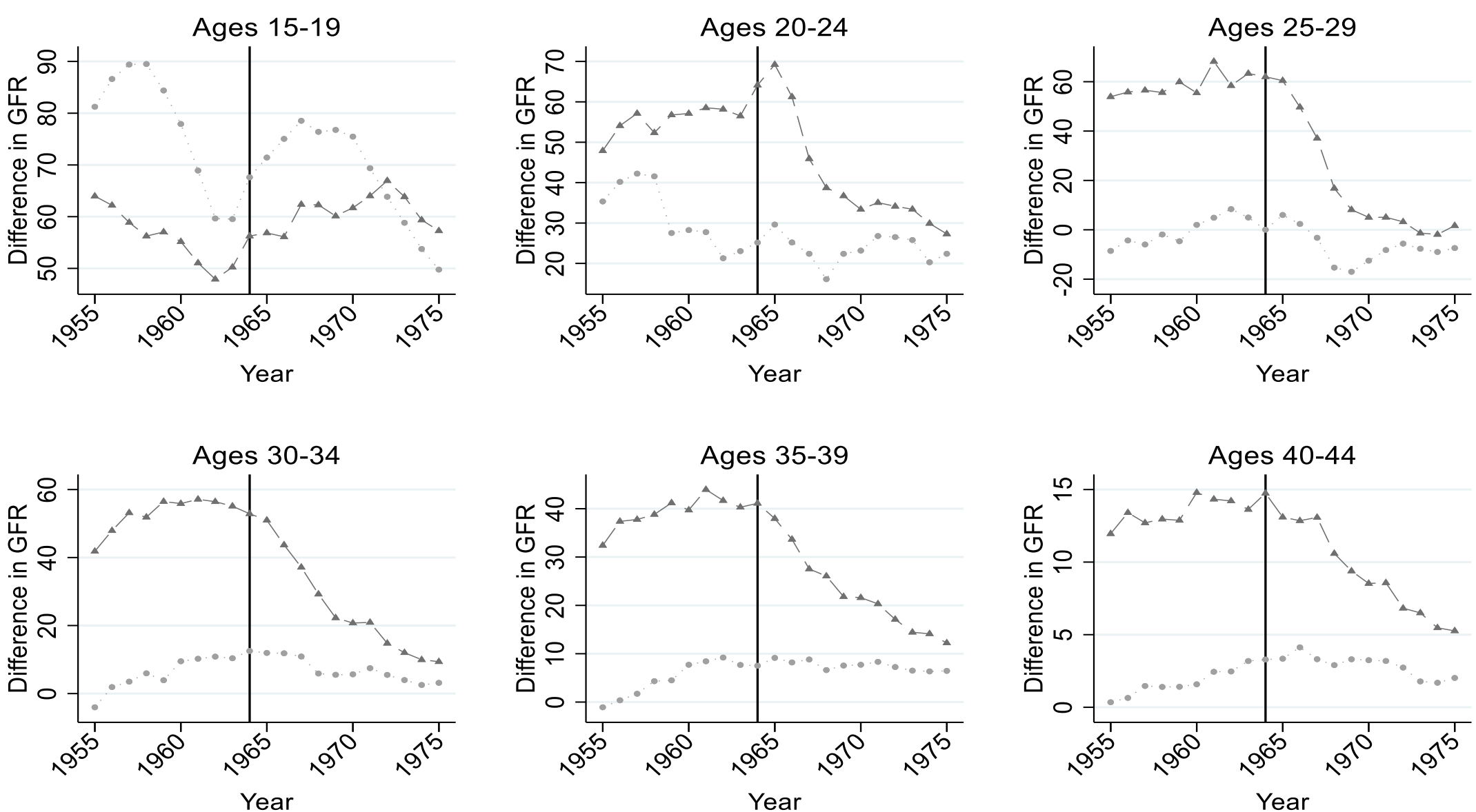

Northern Black - Northern White

- $\_$Southern Black - Southern White

Notes: Figure displays trends in the black-white general fertility rate gap by region and maternal age. Note that the scale of the vertical axes differ by age group. General Fertility Rates are calculated as the ratio of total live births to women in the specified age range to the population of females in that age range, expressed in thousands. Live birth totals are drawn from Vital Statistics print reports transcribed by the author from 1955-1967 and from Vital Statistics microdata from 1968-1975. Population counts are drawn from the Decennial Census with linear interpolations for 1955-1968, and from the Survey of Epidemiology and End Results (SEER) for 1969-1975. The South consists of Alabama, Arkansas, Florida, Georgia, Louisiana, Mississippi, North Carolina, South Carolina, Tennessee, Texas and Virginia, and the North consists of the balance of the lower 48 states. 


\section{Figure 3: Relative Changes in Completed Fertility}

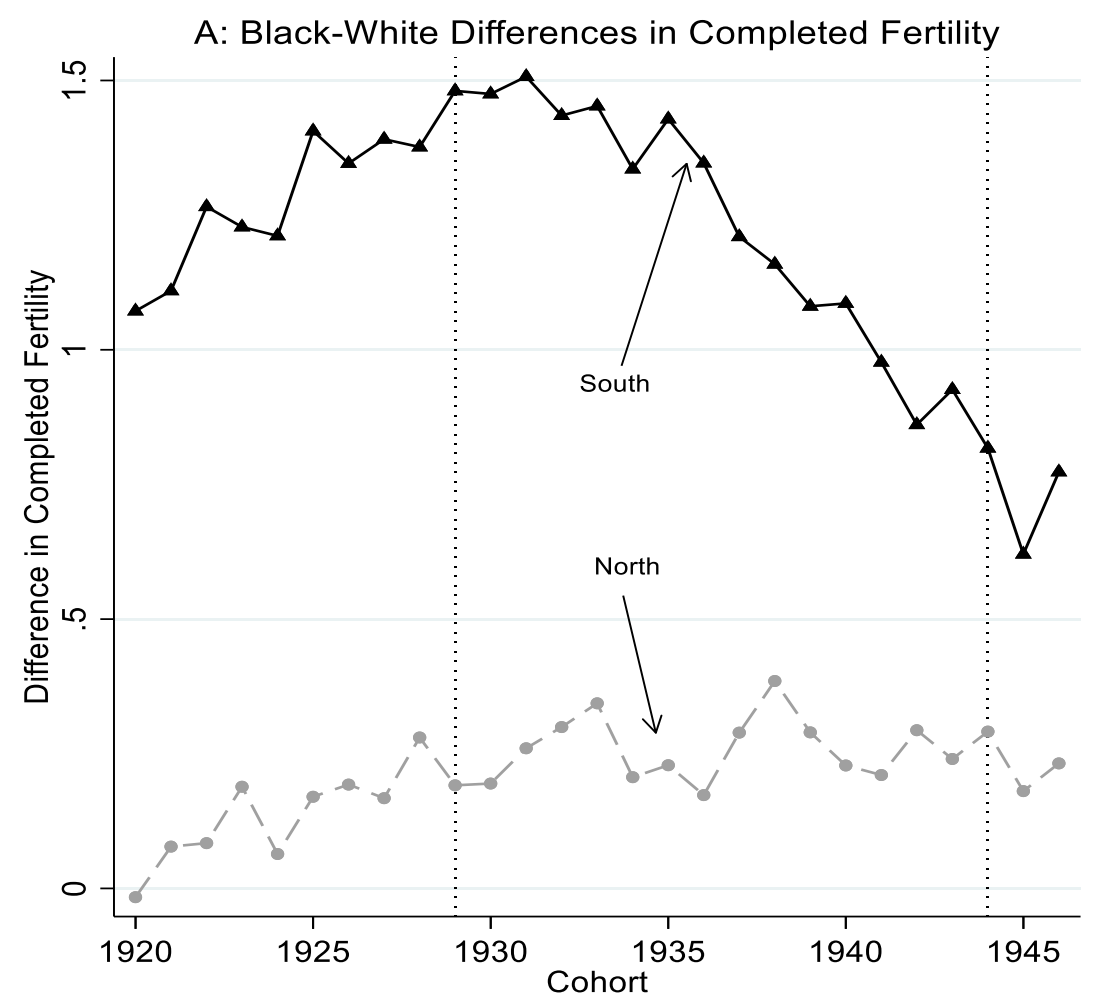

B: Changes in Completed Fertility Distributions
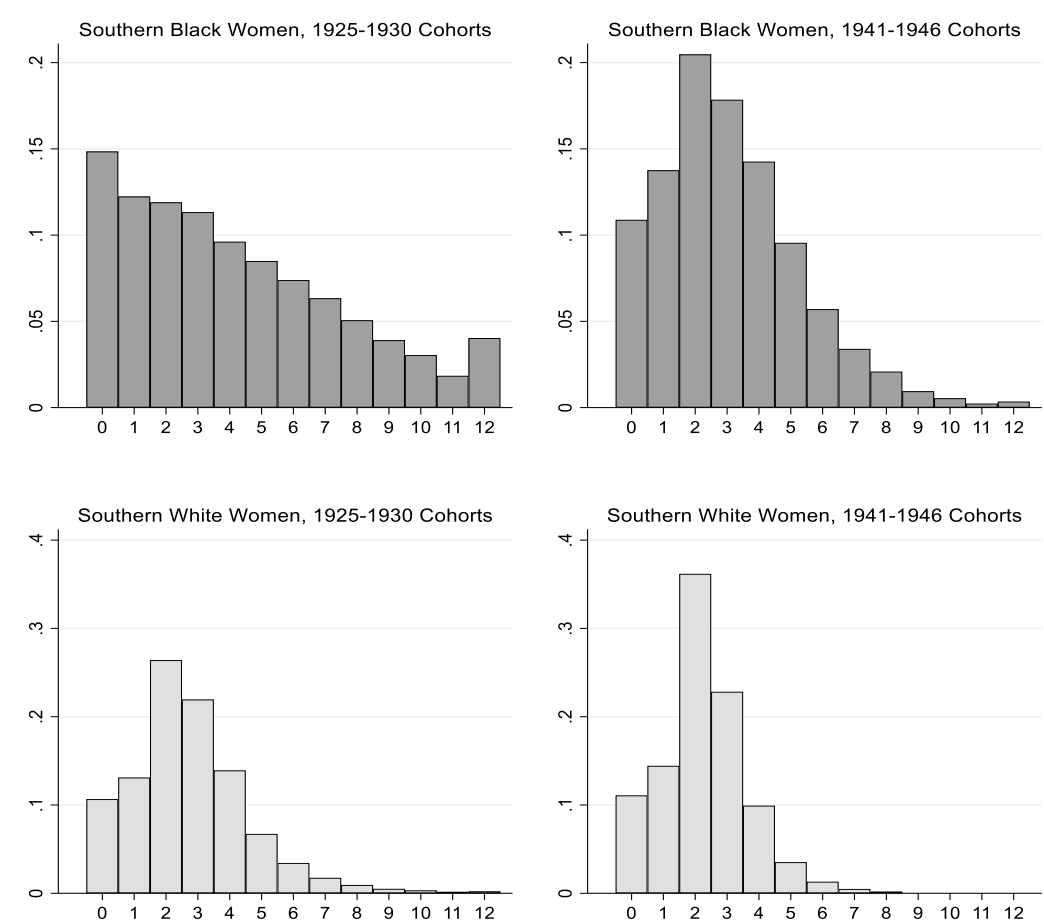

Notes: Panel A displays trends in black-white differences in the mean number of children ever born among female Census respondents ages 44-70, disaggregated by region. Dashed vertical lines indicate the 1929 and 1944 birth cohorts, which is the range of cohorts that were ages 20-35 as of 1964 and whose prime childbearing years therefore spanned 1964. Panel B displays histograms of children ever born among women from the indicated race, region and cohorts. The South consists of Alabama, Arkansas, Florida, Georgia, Louisiana, Mississippi, North Carolina, South Carolina, Tennessee, Texas and

Virginia, the North consists of the balance of the lower 48 states, and individuals who were born in one region but resided in the other at the time of survey are excluded. 
Figure 4: County-Level Convergence in Black-White GFR Differential

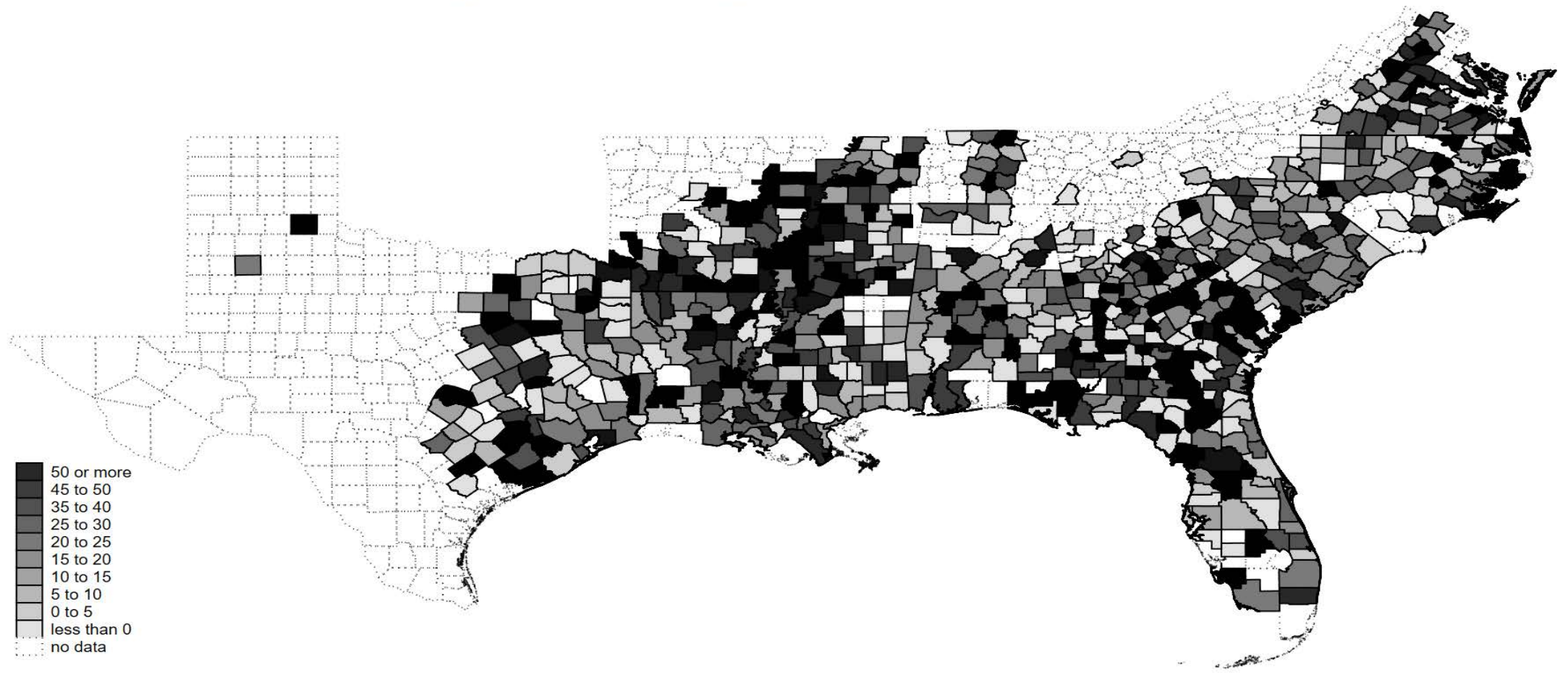

Notes: Figure displays the change in the difference between the general fertility rates of non-whites and whites that occurred in each county between 1964 and 1969. Counties where African Americans constituted less than $99 \%$ of non-whites are excluded. 
Table 1: Decomposing Fertility Convergence

\begin{tabular}{|c|c|c|c|c|c|c|c|}
\hline & (1) & (2) & (3) & (4) & (5) & (6) & (7) \\
\hline & $\begin{array}{c}\text { Covariate } \\
\text { Changes, } \\
\text { Southern Blacks }\end{array}$ & $\begin{array}{c}\text { Covariate } \\
\text { Changes, } \\
\text { Southern Whites }\end{array}$ & $\begin{array}{l}\text { Unconditional } \\
\text { Fertility Change, } \\
\text { Southern Blacks }\end{array}$ & $\begin{array}{l}\text { Conditional } \\
\text { Fertility Change, } \\
\text { Southern Blacks }\end{array}$ & $\begin{array}{l}\text { Unconditional } \\
\text { Fertility Change, } \\
\text { Southern Whites }\end{array}$ & $\begin{array}{c}\text { Conditional } \\
\text { Fertility Change, } \\
\text { Southern Whites }\end{array}$ & Decomposition \\
\hline Year $=1970$ & & & $\begin{array}{l}-38.32 \\
(2.15)\end{array}$ & $\begin{array}{l}-20.71 \\
(2.57)\end{array}$ & $\begin{array}{l}-25.20 \\
(1.88)\end{array}$ & $\begin{array}{l}-21.45 \\
(1.61)\end{array}$ & \\
\hline \multirow{2}{*}{$\begin{array}{l}\text { Own Income } \\
\text { (thousands) }\end{array}$} & 7.626 & 4.389 & & -0.28 & & 0.03 & \\
\hline & $(0.814)$ & $(0.323)$ & & $(0.07)$ & & $(0.01)$ & -4.86 \\
\hline \multirow{2}{*}{$\begin{array}{l}\text { Family Income } \\
\text { (thousands) }\end{array}$} & 21.700 & 14.895 & & -0.19 & & -0.10 & $(0.80)$ \\
\hline & $(2.802)$ & $(1.140)$ & & $(0.02)$ & & $(0.00)$ & \\
\hline \multirow{2}{*}{ Rural } & -0.094 & -0.084 & & -0.85 & & -1.42 & \\
\hline & $(0.016)$ & $(0.016)$ & & $(2.49)$ & & $(1.40)$ & -1.05 \\
\hline \multirow{2}{*}{ Urban } & 0.077 & -0.000 & & -13.09 & & -0.33 & $(0.32)$ \\
\hline & $(0.015)$ & $(0.021)$ & & $(3.69)$ & & $(1.52)$ & \\
\hline Labor Force & 0.042 & 0.079 & & -49.08 & & -64.91 & 3.08 \\
\hline Participation & $(0.010)$ & $(0.005)$ & & $(3.77)$ & & $(1.17)$ & $(0.33)$ \\
\hline \multirow{2}{*}{ High School Graduate } & 0.089 & 0.040 & & 24.69 & & 22.15 & \\
\hline & $(0.004)$ & $(0.008)$ & & $(5.75)$ & & $(1.75)$ & \\
\hline \multirow{2}{*}{ Some College } & 0.023 & 0.026 & & 18.95 & & 30.61 & 0.38 \\
\hline & $(0.002)$ & $(0.001)$ & & $(4.53)$ & & $(2.33)$ & $(0.40)$ \\
\hline \multirow{2}{*}{ College Graduate } & 0.010 & 0.017 & & 33.39 & & 51.53 & \\
\hline & $(0.002)$ & $(0.001)$ & & $(6.67)$ & & $(3.62)$ & \\
\hline \multirow{2}{*}{ Married } & -0.084 & -0.052 & & 58.68 & & 45.36 & \\
\hline & $(0.005)$ & $(0.008)$ & & $(2.77)$ & & $(2.24)$ & -11.39 \\
\hline \multirow{2}{*}{ Never Married } & 0.082 & 0.039 & & -195.50 & & -183.91 & $(1.93)$ \\
\hline & $(0.007)$ & $(0.007)$ & & $(5.66)$ & & $(4.41)$ & \\
\hline \multirow{2}{*}{ Age } & -1.245 & -1.081 & & -7.65 & & -8.83 & -0.03 \\
\hline & $(0.089)$ & $(0.075)$ & & $(0.31)$ & & $(0.22)$ & $(0.96)$ \\
\hline Observations & 145,257 & 435,139 & 145,257 & 145,257 & 435,139 & 435,139 & 580,396 \\
\hline \multicolumn{8}{|c|}{$\begin{array}{l}\text { Notes: Sample includes black and non-Hispanic white females ages 14-44 from the } 1960 \text { and } 1970 \text { Decennial Censuses who were both born and were currently } \\
\text { residing in either Alabama, Arkansas, Florida, Georgia, Louisiana, Mississippi, North Carolina, South Carolina, Tennessee, Texas or Virginia. Each entry in Columns } \\
1 \text { and } 2 \text { comes from a separate bivariate regression with the variable indicated in the row as the dependent variable and a } 1970 \text { indicator as the independent variable. } \\
\text { The coefficients therefore estimate the change in the listed characteristics occurring between } 1960 \text { and } 1970 \text { within the indicated population. The dependent variable } \\
\text { in Columns 3-6 is an indicator of having an own-child under age one currently in the household, multiplied by 1,000. The coefficients therefore estimate the effect of } \\
\text { each independent variable on the general fertility rate within the indicated population. The decomposition entries reported in Column } 7 \text { are calculated by multiplying } \\
\text { the change in each covariate (Columns } 1 \text { and } 2 \text { ) by its conditional association with the GFR (Columns } 4 \text { and } 6 \text { ), subtracting this product among southern whites from } \\
\text { the analogous product among southern blacks, and summing these differences over the sets of covariates measuring earnings, residence-type, labor force } \\
\text { participation, education, marital status, and age. The omitted residence-type category is suburban, the omitted education category is less than high school, and the } \\
\text { omitted marital status category is divorced/separated/widowed. All standard errors are calculated using the formulas derived by Gelbach (2016) with clustering by } \\
\text { state of residence and are reported in parentheses. }\end{array}$} \\
\hline
\end{tabular}




\title{
Online Appendices: Fertility Decline in the Civil Rights Era
}

\author{
Owen Thompson
}

I am very grateful to the authors of Acharya, Blackwell \& Sen (2016); Almond, Hoynes \& Schanzenbach (2011); Bailey (2012); Bailey \& Goodman-Bacon (2015); Cascio, Gordon, Lewis \& Reber (2010); and Project HAL (2019) for making data on county characteristics that is used in these appendices available. All data and programs needed to replicate the results in these appendices are available on the author's personal website, https://sites.google.com/site/othompsonecon. 


\title{
Online Appendix A: Robustness and Extensions, General Fertility Rate Trends
}

\author{
Alternative Regional Definitions
}

The baseline results in Figure 1 defined the South as the 11 states of the former confederacy (Alabama, Arkansas, Florida, Georgia, Louisiana, Mississippi, North Carolina, South Carolina, Tennessee, Texas and Virginia) and the North as the balance of the lower 48 states. However, reasonable alternative regional definitions exist and could yield different results. This possibility is explored in Figure A1.

Panel A of Figure A1 reproduces the baseline results from Figure 1B for reference. Panel B of Figure A1 reports results where five "border states" (Delaware, Kentucky, Maryland, Oklahoma and West Virginia) are included in the South rather than the North. Panel C excludes these five border states entirely. Panel D follows Chay et al. (2009) and uses seven "Rust-Belt" states (Illinois, Indiana, Missouri, New York, Ohio, and Pennsylvania) as the northern control group, rather than all non-southern states, which may be preferable since the Rust Belt is geographically proximate to the South and has a large African American population. In all cases, the relative trends in black-white GFR gaps are virtually identical to the baseline trends.

Figure A2 assesses heterogeneity within the 11 states of the former confederacy by plotting black-white GFR gap trends on a state-by-state basis. While these state-level trends are unsurprisingly somewhat noisier than the trends at the regional level, all 11 states experience a clear post-1964 reduction in black-white GFR differences. Note that Figure 4 of the main paper provides even finer geographic disaggregation by mapping changes in the black-white GFR gap occurring between 1964 and 1969 across the 712 southern counties with available data.

Exclusion of Counties with Substantial Non-Black Minority Populations

Another robustness related issue is that Vital Statistics from the study period only disaggregate maternal race into white and non-white, such that non-black racial minorities are combined with African Americans. While blacks were in most cases the largest minority population in the studied context, there may be some concern that this rough aggregation of racial and ethnic identification affects the findings, particularly since Texas, Florida and many western states with substantial Hispanic populations are included in the analysis. Several southern states also have significant Native American populations that could plausibly impact the findings. To address this issue, Figure A3 reports the results of re-estimating Figure 1B while excluding counties where African Americans constituted less than $99 \%$ of the county's non-white population, such that the vast majority of non-whites in the utilized sample are African American. ${ }^{1}$ The level GFR difference outside of the South is modestly higher after this restriction, but all relevant trends are virtually unchanged

Triple-Difference Specifications

The baseline findings in Figure 1 showed large declines in the black-white fertility gap within the South, and also showed that no such change in the fertility gap occurred in the North. The choice to report the findings as trends in the black-white gap disaggregated by region was made primarily for graphical and expositional clarity, and it is conceptually equivalent to consider southern blacks to be the "treatment group" while using the other three race-by-region groups as control groups that jointly define counterfactual fertility trends for southern blacks in a triple-difference framework.

In particular I have estimate regressions of the following form:

\footnotetext{
${ }^{1}$ The reason this exclusion was not made in the baseline results is that race-specific natality data was suppressed in counties where non-whites constituted less than $10 \%$ of the population, so that state-level aggregations provide a more comprehensive measure.
} 
Fertility $_{\text {rjy }}=\beta_{1}$ Black $+\beta_{2}$ South $+\gamma_{55} Y 1955+\gamma_{56} Y 1956+\ldots+\gamma_{75} Y 1975+$

$\beta_{3}($ Black $\times$ South $)+\lambda_{55}($ Black $\times Y 1956)+\lambda_{56}($ Black $\times Y 1956)+\ldots+\lambda_{75}($ Black $\times Y 1975)+\rho_{55}($ South $\times$ Y1956) + $\rho_{56}\left(\right.$ South $\times$ Y1956) $+\ldots \rho_{75}($ South $\times Y 1975)+$

$\delta_{55}\left(\right.$ Black $\times$ South $\times$ Y1956) $+\delta_{56}($ Black $\times$ South $\times$ Y1956 $)+\ldots+\delta_{75}($ Black $\times$ South $\times$ Y1975 $)+\varepsilon_{r j y}$

In this specification Fertility Fjy $_{\text {is }}$ the GFR for racial group $r$ (either black or white) region $j$ (either southern or northern) and year $y$ (ranging from 1955-1975 and omitting 1964). The independent variables are dummies indicating being black (Black), southern residence (South) and year of observation (Y1955, Y1956,...,Y1975); all possible two way interactions of Black, South and the year dummies; and the three-way interactions of Black, South and the year dummies. The coefficients of interest are the triple-interactions of Black, South and year $\left(\delta_{y}\right)$ which estimate the fertility rate of southern blacks relative to the other groups in each year from 1955 to 1975 (with 1964 as the reference year), after flexibly controlling for independent effects of race, region and year.

The full set of results from estimating this specification are reported in the first column of Table A1, and the coefficients on the three-way interaction terms are plotted in Panel A of Figure A4. ${ }^{2}$ As expected given the trends shown in Figure 1 of the main paper, Table A1 and Figure A4 find a clear trend break in 1964, with the GFR of southern black women declining by approximately 20 births per thousand women of childbearing age between 1964 and 1970, relative to women in other race-by-region groups.

The triple-difference framework is also amenable to analyzing percent changes in fertility, rather than level changes, by simply replacing the level GFR with the natural log of the GFR as the dependent variable in the regression specification. Results of estimating such a model are reported in Column 2 of Table A1 and Panel B of Figure A4. The results indicate that the relative fertility decline of southern blacks between 1964 and 1970 was approximately 15\%, and the other qualitative conclusions hold in the logged specification. This suggests that relative black fertility reductions did not solely reflect the fertility of southern black women having "further to fall" than other groups.

\section{Online Appendix B: Robustness and Extensions, Completed Fertility Trends}

\section{Inter-Regional Migration}

The baseline completed fertility results from Figure $2 \mathrm{~A}$ of the main paper excluded all individuals who were born in one region but resided in the other when they were surveyed at ages 44-70. While this restriction is a reasonable baseline, the issue of inter-regional migration warrants additional attention given the large-scale and heavily selected northern migration occurring among African Americans in the studied cohorts.

Two natural alternatives are to retain inter-regional migrants but define southern status on the basis of either birth region or current region of residence. Replications of Figure $2 \mathrm{~A}$ using these alternative definitions are respectively shown in Panels A and B of Figure A5. The most important feature of Figure A5 is that under either regional classification approach there is a clear reduction in the black-white completed fertility gap in the South but not the North.

\footnotetext{
${ }^{2}$ Note that because the regression specification is estimated with data at the race-region-year level, which is the same level as the interactions of interest, the $R^{2}$ of this regression is equal to 1 and the coefficient's standard errors are not estimable. If the specification is instead estimated with data at the state or county level the coefficients on the triple-interaction terms are statistically significant at conventional levels, but these geographic disaggregation are arbitrary and the resulting standard errors are therefore difficult to interpret, leading me to prefer the results reported in Table A1 and Figure A4.
} 
Another notable feature of Figure A5 is that relative convergence is noticeably stronger when region is defined on the basis of residence (Panel B) than on the basis of birth (Panel A). In practice the primary difference between the samples used in Panels A and B is that the sample in Panel B excludes black women who were born in the South but lived in the North when they were surveyed at ages $44-70$. This is because $29 \%$ of black women in the sample were born in the South but lived in the North when surveyed, and are therefore included in the sample from Panel A but not the sample from Panel B, whereas only $2 \%$ of black women in the overall sample were born in the North but lived in the South when surveyed, and only $3 \%$ of white women in the overall sample were born in the South but lived in the North when surveyed. The differences in the patterns observed in Panels A and B therefore imply that decreases in fertility were relatively weak among northern-migrating black women.

This is examined more directly in Figure A6, which reports trends in completed fertility separately for southern-born black women who had left for the North by the time they were surveyed ("leavers") versus southern-born black women who had remained in the South at the time of survey ("stayers"). Figure A6 shows that completed fertility among stayers was higher than among leavers across all the studied cohorts, and that the completed fertility declines occurring among the post-1930 cohorts were especially strong among stayers, such that the difference between these two groups falls from .65 within the 1930 cohort to .35 in the 1946 cohort.

While interesting, the causes and implications of these differences are difficult to interpret without additional information. On the one hand, the differences in completed fertility between stayers and leavers may simply reflect the greater difficulty of migrating with children, higher levels of socioeconomic status among migrants, or other forms of selection. An alternative (but not mutually exclusive) explanation for the differences shown in Figure A6 is that exposure to post-1964 changes in environmental conditions affected fertility behavior more than exposure to any events occurring in childhood, leading to greater fertility impacts among stayers because they were more likely to have directly experienced the post-1964 social and economic changes occurring in the South. I do note however, that region of residence in 1964 is not directly observed, since the year of migration among individuals not residing in their region of birth is not reported.

It is also difficult to draw strong conclusions from Figures A5 and A6 about the contribution of inter-regional migration to the observed declines in general fertility rates after 1964. While the fact that southern black women with lower fertility propensities were more likely to migrate would lower the overall GFR among African American women residing in the South, the effect of migration on year-specific GFR trends will depend on the magnitude of migration and the degree of fertility-relevant selection among those migrants in the years surrounding 1964, which are not observed. Ultimately, the fact that strong relative fertility reductions are observed using both residence-based and birth-based regional definitions strongly suggests that the observed GFR trends are not purely an artifact of selective inter-regional migration, but the precise impacts of migration are not readily identifiable.

\section{CPS Replications}

As noted, the Census Bureau discontinued the completed fertility question after the 1990 Census, and in conjunction with the standard over-44 age restriction for completed fertility calculations, this data limitation does not allow completed fertility to be calculated beyond the 1946 cohort in Census data. However, completed fertility can be calculated for a broader range of cohorts using the June Fertility Supplements from the Current Population Survey, which was fielded 26 times between 1976 and 2018. 
While the CPS allows for completed fertility to be observed across a wider range of cohorts, it produces much smaller working samples than the Census. Not only are the base sample sizes smaller, but in many years only women ages 18-44 or ages 14-49 were asked their total number of live births, greatly limiting the number of usable observations. As a result of these limitations, it is only possible to observe completed fertility for 405,785 CPS respondents over the relevant cohorts, compared to 2,659,622 in the Census analysis from the main paper. A final issue is that the CPS June Fertility Supplements used highly inconsistent top-coding of total births, ranging from 5 to 20 , which makes the calculation of the mean births particularly erratic.

These data issues notwithstanding, it is useful to extend the series in Figure 3 of the main paper beyond the 1946 cohort, as well as to test whether the main completed fertility findings are replicable in a second, independently drawn sample. As such, Figure A7 replicates Figure 3 of the main paper using CPS data, and does so for the 1920-1960 cohorts in Panel A (rather than 1920-1946), while using the 1945-1950 cohorts as the "post" cohorts for the distributional analyses in Panel B (rather than 1941-1946).

As expected, the completed fertility series shown in Panel A is much more erratic than its Census-based counterpart in Figure 3 of the main paper, but the trends are qualitatively similar, with the black-white gap in completed fertility among southern women falling from approximately 1.5 live births in the 1930 cohort to approximately .5 by the early 1940 s, with no significant changes in the North. Panel A of Figure A7 additionally shows that there was little additional change in relative mean completed fertility through the cohorts of the mid-1950s, with some further declines in black-white gaps in the South after 1955, although these declines are difficult to interpret given the large cross-cohort fluctuations in completed fertility throughout the series. Panel B finds changes in the completed fertility distributions of black and white women in the South that are very similar to those in Figure 3, with a dramatic truncation of the right-tail of the completed fertility distribution but decreases in childlessness for southern black women, and modest substitution from completed fertility levels of 3-4 children ever born into 2-3 children ever born for southern white women.

Overall, the results in Figure A7 indicate that the main paper's completed fertility results were not an artifact of any sampling or data construction issues unique to the Decennial Censuses, and that no large-sale and systematic additional fertility changes appear to have taken place after the 1946 cohort.

Triple-Difference Specifications

As was the case for the general fertility rate results, the completed fertility analysis can be implemented as a triple-difference specification that estimates completed fertility changes across cohorts among southern blacks while differencing out a common region effect, a common race effect, and common cohort effects, effectively using the other three race-by-region groups as controls that jointly define a counterfactual completed fertility trend for southern blacks.

To implement such analyses in a regression framework I estimate a specification very similar to the one from Online Appendix A, but replace the GFR with completed fertility as the dependent variable and replace year dummies with birth cohort dummies:

CompFertility $_{\text {irjc }}=\beta_{1}$ Black $+\beta_{2}$ South $+\gamma_{20} C 1920+\gamma_{21} C 1921+\ldots+\gamma_{46} C 1946+$

$\beta_{3}($ Black $\times$ South $)+\lambda_{20}($ Black $\times$ C1920 $)+\lambda_{21}($ Black $\times C 1921)+\ldots+\lambda_{46}\left(\right.$ Black $\times$ C1946 $+\rho_{20}($ South $\times$ C1920 $)+$ $\rho_{21}($ South $\times C 1921)+\ldots \rho_{46}($ South $\times C 1946)+$

$\delta_{20}($ Black $\times$ South $\times$ C1920 $)+\delta_{21}($ Black $\times$ South $\times$ C1921 $)+\ldots+\delta_{46}\left(\right.$ Black $\times$ South $\times$ C1946) $+\varepsilon_{\text {irjc }}$.

In this specification CompFertilityirjc is the completed fertility of woman $i$ of racial group $r$ (either black or white) region $j$ (either southern or northern) and cohort $c$ (ranging from 1920 to 1946 and omitting 1935). 
The independent variables are dummies indicating being black (Black), southern residence (South) and birth cohort (C1920, C1921,...,C1946); all possible two way interactions of Black, South and the cohort dummies; and the three-way interaction of Black, South and the cohort dummies. The coefficients of interest are the triple-interactions of Black, South and cohort $\left(\delta_{c}\right)$ which estimate the completed fertility of southern black women relative to the other groups in each cohort from 1920 to 1946 (with 1935 as the reference year), after flexibly controlling for independent effects of race, region and cohort.

The full set of results from estimating this specification are reported in Table A2, and the coefficients on the three-way interaction terms are plotted in Figure A8. Because completed fertility trends are estimated using individual level data, standard errors are estimable, and Table A2 reports standard errors clustered at the state level, while Figure A8 displays the $90 \%$ confidence intervals for the triple-interactions. As expected given the trends shown in Figure 3 of the main paper, Table A2 and Figure A8 find large relative reductions in the completed fertility of southern black women from cohorts after 1935 relative to cohort trends among women in other race-by-region groups, with statistically significant relative reductions of approximately .7 live births between the 1935 cohort and the cohorts of the mid-1940s.

\section{Online Appendix C: Robustness and Extensions, Census Decompositions}

\section{The Accuracy of GFR Measures in the Census}

As noted in the main paper, I estimate fertility rates in the Decennial Censuses by restricting the 1960 and 1970 Census samples to females ages 14-44 and observing whether household rosters indicate that these women were living with an own-child under the age of one, then assume that if such a child is present the woman experienced a live birth in the past year. More specifically, I begin with the 1960 and 1970 Census Form 1 and Form 2 samples from IPUMS, then restrict these samples to women who were ages 14-44 at the time of the survey and who were both born in the South and were currently residing in the South. Own children under age one are then identified from the relationship types listed in the household rosters.

While the relationship types available in these samples for both 1960 and 1970 can distinguish parents from grandparents, siblings, or other extended family members, the utilized data does not allow adoptivechildren and step-children to be consistently distinguished from own-children. When a woman's step-child or adoptive-child are misidentified as their own biological child, the utilized fertility measure will be biased upward, although I note that at an aggregate level there will often be an offsetting under-count for the step/adoptive child's non-resident biological mother. ${ }^{3}$ On the other hand, the utilized fertility measure will be biased downward when a child dies before their first birthday and is not enumerated by the Census during the period they were alive.

Palmore \& Gardner (1983) note that in practice the latter source of bias is typically stronger than the former, so that roster-based fertility measures from household surveys usually find lower fertility levels than Vital Statistics based measures, but the sign and magnitude of any bias will of course depend on the particular data and context. To assess the accuracy of the survey based fertility measures used here, Table A3 compares the GFR levels from the Census versus Vital Statistics data sets that were used in the main paper. The table reports GFR levels from these two data sources for each race-by-region group and for 1960 and 1970, as well as the fertility change occurring within each race-by-region group between 1960 and 1970 .

\footnotetext{
${ }^{3}$ To help mitigate this source of bias, I drop observations where the woman with an own-child under age one reported never having had a live birth, as well as women residing in group quarters or multifamily households, where it is more difficult to ascertain precise relationship types.
} 
The first row of Table A3 reports GFR estimates in the two data sets for southern black women. In the Vital Statistics records, the GFR of women in this population fell from 160 in 1960 to 118 in 1970, a decline of 41. Table A3 shows that Census-based GFR estimates for this population are substantially lower overall, with a GFR estimate of 126 in 1960 and 86 in 1970. However, the estimated 40 birth GFR decline between 1960 and 1970 is virtually identical to the Vital Statistics estimate of 41 . This is reassuring, given that the analysis in the main paper is primarily concerned with group specific fertility changes over time.

Vital Statistics GFR estimates are similarly higher than Census based estimates for the other three groups as well, although these level differences are typically smaller than what was observed for southern blacks. Most importantly, the changes between 1960 and 1970 are again very similar across Vital Statistics and Census records. Specifically, the GFR of southern white women was estimated to fall by 24 in Vital Statistics records versus 27 in Census records; the GFR of northern black women was estimated to fall by 34 in Vital Statistics records versus 31 in Census records; and the GFR of northern white women was estimated to fall by 29 in Vital Statistics records versus 31 in Census records. Overall the findings in Table A3 are consistent with Census records having a moderate negative bias relative to Vital Statistics records, but with the magnitude of that bias being relatively constant over time for all groups, allowing for credible analyses of relative trends.

The most obvious potential explanation for the level differences in GFR estimates is that some children under age one die before being enumerated by the Census, and to investigate this issue Table A4 adjusts the Census estimates from Table A3 for infant mortality rates. Specifically, Columns 1-3 of Table A4 report infant mortality rates by race, region and year, while Columns 4-6 of Table A4 use these rates to adjust the Census GFR estimates. For example among southern black children born in 1960 there were 47 infant deaths per thousand live births, or 4.7\% (Column 1). This suggests that while Census records show that 126 out of every 1,000 southern black women of childbearing age had an own-child living with them in 1960, an additional $126 \times .047 \approx 6$ women may have given birth to a child who died prior to enumeration. Column 4 of Table A4 simply adds 6 to the baseline GFR estimate of 126 . This process is then repeated for each race, region and year.

Table A4 finds that while some of the differences in estimated GFR levels between Vital Statistics and Census records can be attributed to infant mortality, the changes are typically quite modest, and the estimated changes between 1960 and 1970 are very similar after adjusting for infant mortality. This is primarily because while infant mortality in the study period was extremely high by normative and modern standards, infant deaths were still a relatively rare event, such that the impact of infant mortality of aggregate fertility estimates is modest.

Other potential reasons for the level differences in Table A3 are that some young children live with individuals other than their biological mothers (for instance their fathers or grandparents) and imperfect sampling techniques in the 1960 and 1970 Censuses. In any case, for present purposes it is sufficient that any such biases are relatively consistent over time within race-by-region groups, and Table A3 suggests that this is the case.

\section{Alternative Decomposition Specifications}

Table A5 reports the results of several robustness and specification checks for the decomposition results in Table 1 of the main paper. Column 1 of Table A5 reproduces the baseline decomposition results from Column 7 of Table 1 in the main paper for reference. For brevity the remaining columns report final decomposition results under alternative specifications, rather than all constituent elements of the decompositions. Interested readers can reproduce each component of the alternative decompositions using the provided data and code. 
The baseline decomposition restricted the sample to individuals who were residing in the region of their birth to minimize the impacts of selective migration. Column 2 of Table A5 includes these individuals, and classifies their region based on current residence, which matches the regional classification used in Vital Statistics data. The results are very similar to the baseline findings that excluded inter-regional migrants.

As noted in the main paper, changes in marital status had by far the most explanatory power of the included covariates in the baseline results. This was because reductions in marriage rates between 1960 and 1970 were moderately stronger for southern black women than southern white women (a reduction of 8.4 vs. 5.2 percentage points) and because there is unsurprisingly a very strong association between marriage and fertility. However, this strong association may be due to reductions in fertility causing lower marriage rates rather than lower marriage reducing fertility, making it arguably preferable to exclude marital status from the decomposition, and decomposition results that are identical to the baseline model but exclude the marriage covariates are reported in Column 3 of Table A5.

The exclusion of the marriage covariates greatly reduces the overall explanatory power of the covariate vector. Specifically, while adding covariates reduced the estimated GFR convergence by 13.9 births with marital status indicator included, the analogous reduction is only 3.4 births when marital status indicators are excluded from the covariate vector. Despite this large reduction in total explanatory power, the estimated contributions of earnings, urbanization and labor force participation are generally similar to those in the baseline decomposition. In particular, the estimated reduction in the black-white GFR gap among southern women that is attributable to changes in earnings goes from 4.9 births with marriage included to 3.1 births with marriage excluded; the estimated reduction due to urban versus rural residence goes from 1.1 with marriage included to .81 with marriage excluded; and the estimated contribution of labor force participation goes from 3.1 with marriage included to 3.6 with marriage excluded. These results indicate that while the appropriateness of including marriage as a covariate is questionable and does have large impacts on the decomposition results, the qualitative conclusion that relative changes in the earnings and urban residence status of southern black women between 1960 and 1970 exerted a significant negative influence on blackwhite fertility gaps, while changes in relative female labor force participation rates had the opposite effect, hold regardless of marital status's inclusion as as covariate.

Similar to marital status, a high degree of reverse-casualty may be responsible for the observed association between female labor force participation and fertility. Column 4 of Table A5 reports results that additionally exclude the labor force participation controls, and find that the estimated contributions of earnings and urban residence are nearly unchanged.

The baseline decomposition assessed changes in the GFR gap between southern blacks and southern whites. But as was the case in the prior analyses, it is also reasonable to use northern blacks as the control group or to estimate triple-difference models that compare southern blacks to the other three race-by-region cells, and results of these alternative comparisons are reported in Columns 5 and 6 of Table A5.

The decomposition reported in Column 5 is structurally similar to the decomposition reported in Table 1 of the main paper, but uses the sample of African Americans in both regions and replaces the black indicator with a South indicator throughout the decomposition.

When using this alternative control group, earnings continue to explain a substantial portion of the observed reduction in the relative fertility of southern black women. In particular, Column 5 indicates that individual and family level earnings jointly "explain" a statistically significant 5.2 birth reduction in the GFR gap 
between southern and northern blacks. Interestingly, both labor force participation and marriage have much less predictive power when using northern blacks as the comparison group. This is because while these characteristics are strongly associated with fertility for blacks in both regions, changes in their levels between 1960 and 1970 were not substantially stronger among southern blacks than among northern blacks. In particular, while the labor force participation rate of fertile-aged southern black women increased by 4.2 percentage points among southern black women between 1960 and 1970 (see Table 1), it increased by only 2.9 percentage points among northern black women (not shown). Similarly, while marriage rates decreased by 8.4 percentage points among southern black women between 1960 and 1970, the analogous change for northern black women was 11.1 percentage points (not shown).

The final column of Table A5 reports the results of a specification that pools observations from both races and both regions then decomposes the sources of differential fertility changes among southern blacks. In practice this is implemented by including the three way interaction of a 1970 indicator, a black indicator and a South indicator as the independent variable of interest (as well as main effects and all possible two way interactions of these variables), then observing the extent to which the coefficient on this triple interaction falls when the covariate vector is included in the model (as well as interactions between the covariates and black and south indicators). As in Column 5, the estimated impact of marriage and labor force participation change substantially in this specification, but there is a large and robust reduction in the relative fertility of southern blacks attributed to earnings, and a smaller but still significant effect attributed to urbanization.

\section{Online Appendix D: Analyses of Geographic Heterogeneity}

Figure 4 of the main paper showed substantial spacial heterogeneity in the magnitude of post-CRA racial fertility convergence. To provide a more systematic accounting of which county characteristics were most strongly correlated with the strength of fertility convergence, I assemble a detailed data set with various potentially relevant county characteristics, then estimate the county-level associations between these characteristics and the strength of local fertility convergence. In particular, I estimate regressions of the following form:

$$
\Delta \text { FertilityGap }=\beta X_{c}+\varepsilon_{c}
$$

where $\Delta$ FertilityGap $c$ is the change in the black-white GFR gap occurring in county $c$ between 1964 and 1969 and $X_{c}$ measures a characteristic of county $c$ that potentially influenced the strength of fertility convergence. I first report the bivariate association between fertility decline and various county characteristics while excluding the other studied characteristics, then report a single specification that includes all of the studied

county characteristics simultaneously. As a robustness check I additionally estimate and report specifications that include a control vector with each county's total black population, total population of all races, and a state fixed-effect, which will help to account for basic county characteristics that may confound the association between the studied factors and fertility, such as the presence of a population center, the county's overall racial composition, and state-level policies.

Results of this exercise are reported in Table A6, using an estimation sample that includes 675 counties with non-missing data on all of the studied covariates. To facilitate comparisons across county traits measured in different units, all of the $X_{c}$ variables are standardized into z-scores, such that $\beta$ can be interpreted as the 
change in the strength of fertility convergence associated with a one standard deviation increase in $X_{c}$. The mean and standard deviation of each utilized measure are reported at the bottom of Table A6 for reference. Standard errors are clustered at the state level and reported in parentheses.

I begin by estimating the association between fertility convergence and school desegregation and hospital access, with results reported in Columns 1 and 2 of Table A6.

School desegregation data is drawn from Office of Civil Rights (OCR) compliance surveys and the Southern Education Reporting Service (SERS), a consortium of southern newspaper editors, and was primarily collected and generously made available by Sarah Reber (see Reber 2010; Cascio et al. 2010) with some additional data transcription by the author. ${ }^{4}$ I measure the level of school desegregation in a given year as the fraction of black students attending a school that also enrolled whites, then calculate the change in this measure occurring between 1964 and 1969 for each county. The descriptive statistics at the bottom of Column 1 indicate rapid school integration: In the typical county, the fraction of African American students attending an integrated school increased by 58 percentage points between 1964 and 1969 .

I measure hospital access in a given year as the black-white difference in the fraction of births which occurred in a hospital, which was recorded in the same Vital Statistics data used for the baseline fertility analyses, and again calculate the change in this measure between 1964 and 1969 for each county. The descriptive statistics at the bottom of Column 2 show that this gap fell by 16 percentage points between 1964 and 1969 (reflecting an increase from $73 \%$ to $89 \%$ among blacks and a constant rate of $99 \%$ among whites). ${ }^{5}$

The regression results for school desegregation in Column 1 indicate that a standard deviation increase in the magnitude of local school desegregation increased the strength of black-white fertility convergence by a .63 births, while the results in Column 2 indicate that a standard deviation increase in the magnitude of local hospital access increased the strength of convergence by 2.44 births. The magnitude of fertility convergence in the average county within the estimation sample was 27 births, so that these coefficients translate into convergence levels that were $2-9 \%$ stronger than average, but neither association is statistically significant at conventional levels. ${ }^{6}$

I next estimate the associations between fertility convergence and the local presence of potentially relevant federal programs, specifically Medicaid, the Food Stamp Program, Head Start and the Family Planning Program, which may have directly or indirectly changed the costs of investing in children's human capital or avoiding a birth. The presence of Medicaid and the Food Stamp Program are measured as the average level of per-capita spending on these programs between 1964 and 1969, Head Start presence is measured

\footnotetext{
${ }^{4}$ The OCR surveys were first fielded in 1968 as part of the federal government's efforts to monitor compliance with the CRA, and collected school-level counts of students, disaggregated by race. The OCR sample for most years included approximately 75,000 individual schools located in 8,000 school districts nationwide. All school districts with enrollment greater than 3,000 were included in the sample, and districts with enrollment between 300 and 3,000 were subject to probability sampling proportionate to their enrollment totals. Additionally, school districts of "special interest" to the OCR were included irrespective of size, typically those with histories of compliance failure, which in practice meant that a large majority of southern school districts were included. I supplement the OCR data with the SERS data to measure baseline desegregation levels in 1964, although in practice virtually all of the schools in the 11 states of the former Confederacy studied here were fully segregated as of 1964 , with less than $3 \%$ of black students attending desegregated schools during the 1964 school year.

${ }^{5} \mathrm{An}$ alternative measure of health care access is the infant mortality rate (IMR), which fell by approximately 10 infant deaths per 1,000 live births among southern blacks between 1964 and 1969, but by only 3 infant deaths among southern whites over the same period. Results when the IMR is used in place of (or in addition to) the in-hospital birth rate are qualitatively similar to those shown below, but I prefer the in-hospital birth rate because the race-specific IMR is unavailable for approximately 30 of the counties in the estimation sample.

${ }^{6}$ The 27 birth reduction in the black-white fertility gap in the average county is greater than the 20 birth convergence from 1964-1969 shown in Figure 1B because the analysis from Table A6 gives all counties equal weight, and convergence was somewhat stronger in less populous counties.
} 
with average spending per four year-old between 1964 and 1969, and the presence of the Family Planning Program is measured using an indicator of whether this program was operational in each county at some point between 1964 and 1969. Data on the local spending and operations of these programs are drawn from archival records which were collected and generously made available by Almond, Hoynes \& Schanzenbach (2011), by Bailey (2012), and by Bailey \& Goodman-Bacon (2015). The means in the final row of Table A6 indicate that from 1964-1969 the average county in the sample had spending of $\$ 36.27$ per resident for Medicaid, $\$ 7.24$ per resident for Food Stamps, and $\$ 491.25$ per four year-old for Head Start, and that the Federal Family Planning Program was present in 16\% of counties at some point from 1964-1969.

Columns 3-6 of Table A6 report the results for these four programs, and find that all four were associated with stronger fertility convergence, with three of the four associations statistically significant at conventional levels. With the exception of the Family Planning Program, the magnitudes of the associations are qualitatively large. While potential biases from selection, non-random migration, measurement error and other potential issues prevent strong causal inferences from being drawn from these associations, the fact that counties with greater exposure to these programs experienced systematically stronger relative black fertility declines is consistent with War on Poverty and Great Society programming meaningfully contributing to the observed fertility convergence.

Among the most important effects of the Civil Rights Movement, but also among the most difficult to quantify, are the social and psychological ramifications of full citizenship and equal protection under the law. For example the act of voting or riding in the front of public buses had few direct economic consequences, but obviously carried great social significance, and likely had meaningful impacts on optimism and expectations about future levels of opportunity that could have plausibly led southern African Americans to reduce fertility levels and invest more heavily in smaller numbers of children.

An indirect method of evaluating this possibility is to test whether fertility convergence was stronger in areas of the South that had the most severe histories of state-sponsored discrimination and racial violence. To do so, I estimate the association between fertility convergence and each county's antebellum slave density, measured as the ratio of enslaved African Americans to the total county population in 1860, and the number of lynchings per 1,000 black residents occurring between 1882 and 1930. Slave densities are calculated with 1860 Census data and follow the method of Acharya, Blackwell \& Sen (2016) to create historically consistent county boundaries. Lynching data comes from the Historical American Lynching Data Collection Project (Project HAL 2019), and includes all known lynchings in which the victim was African American and the mob was white. The provided descriptive statistics indicate that for the average county in the estimation sample $43 \%$ of the 1860 population consisted of enslaved African Americans, and .48 lynchings per 1,000 black residents had occurred during the Reconstruction and Jim Crow periods.

The results in Column 7 of Table A6 indicate that a standard deviation increase in 1960 slave density is associated with a statistically significant increase in post-1964 fertility convergence of 4.32 births, which is approximately $16 \%$ stronger than convergence in the average county, and is the strongest association among the studied characteristics. Column 8 finds that a standard deviation increase in per-capita lynchings is associated with a statistically significant 2.24 birth increase in the magnitude of fertility convergence, also one of the stronger observed associations. Again, while the current exercise is primarily descriptive, the presence of such strong associations between historical measures of the intensity of enslavement and racial violence and post-1964 relative black fertility decline is consistent with the possibility that some of the observed change in fertility behavior was a response to the dismantling of the most overt forms of 
state-sponsored racism, rather than solely due to narrower economic incentives such as increases in forgone earnings from parenthood after 1964.

The final column of Table A6 reports the results of a specification that includes all of the studied county characteristics simultaneously, and most of qualitative conclusions are unchanged. The conditional correlation between fertility convergence and school and hospital desegregation are both positive and non-trivial but not statistically significant; the presence and expenditures of newly created social programs are positively associated with fertility convergence and are in some cases statistically significant; and both 1860 slave density and lynching rates have strong and statistically significant correlations with the strength of post-1964 fertility convergence, even conditional on the other county characteristics. Calculating the linear combination of the coefficients in Column 9 for sets of related county characteristics indicates that the combined impact of school integration and hospital access was 4.43 births $(p=.11)$, the combined impact of the studied War on Poverty programs was 4.90 births $(p=.056)$, and the combined impact of historical slave usage and lynchings was 6.45 births $(p=.008)$.

Table A7 repeats the analyses in Table A6, but includes controls for each county's total black population, total all-race population, and state fixed-effects in all of the specifications. The results are qualitatively similar to those in Table A6. 


\section{Appendix References}

Acharya, A., Blackwell, M., \& Sen, M. (2016). The political legacy of American slavery. Journal of Politics, 78(3), 621-641.

Almond, D., Hoynes, H. W., \& Schanzenbach, D. W. (2011). Inside the war on poverty: The impact of food stamps on birth outcomes. Review of Economics and Statistics, 93(2), 387-403.

Bailey, M. J. (2012). Reexamining the impact of family planning programs on US fertility: evidence from the War on Poverty and the early years of Title X. American Economic Journal: Applied Economics, 4(2), 62-97.

Bailey, M. J., \& Goodman-Bacon, A. (2015). The War on Poverty's experiment in public medicine: Community health centers and the mortality of older Americans. American Economic Review, 105(3), 1067-1104.

Cascio, E., Gordon, N., Lewis, E., \& Reber, S. (2010). Paying for progress: Conditional grants and the desegregation of southern schools. Quarterly Journal of Economics, 125(1), 445-482.

Chay, K. Y., Guryan, J., \& Mazumder, B. (2009). Birth cohort and the black-white achievement gap: The roles of access and health soon after birth. NBER Working Paper.

Palmore, J. A., \& Gardner, R. W. (1983). Measuring mortality, fertility, and natural increase: A self-teaching guide to elementary measures: East-West Population Institute, East-West Center.

Project HAL (2019). The Historical Lynching Data Collection Project. http://people.uncw.edu/hinese/HAL/HAL\%20Web\% (retrived 6/2019)

Reber, S. J. (2010). School desegregation and educational attainment for blacks. Journal of Human Resources, 45(4), 893-914. 


\section{Figure A1: Alternative Regional Definitions}
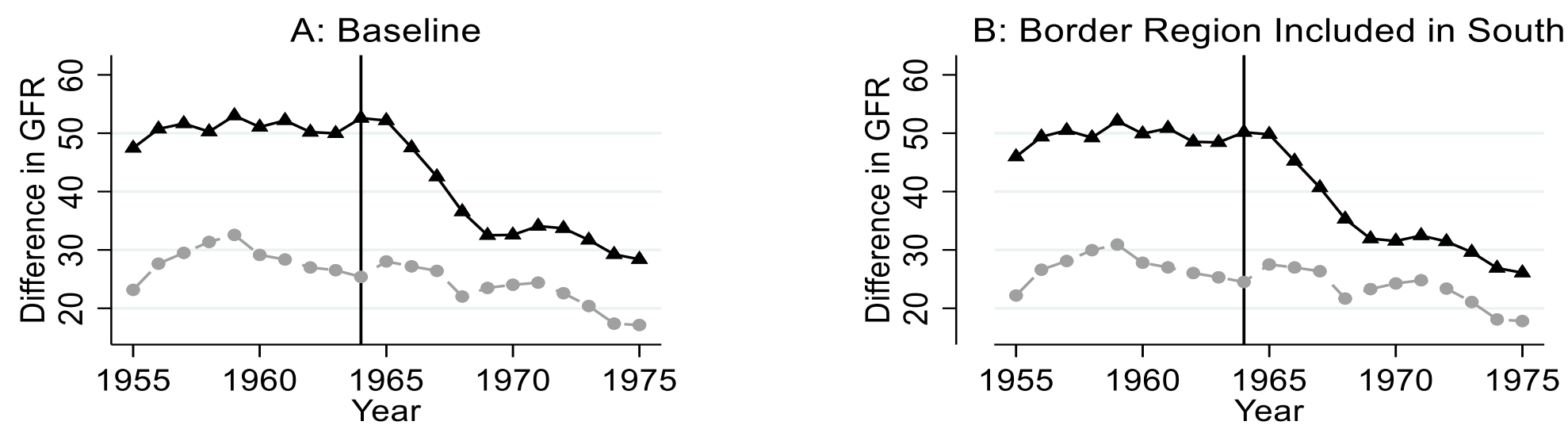

C: Border Region Excluded

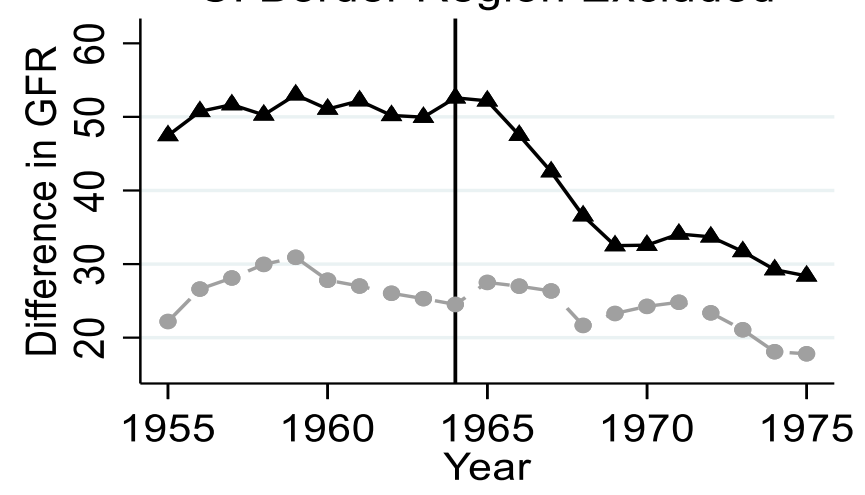

D: North Restricted to Rust-Belt Only

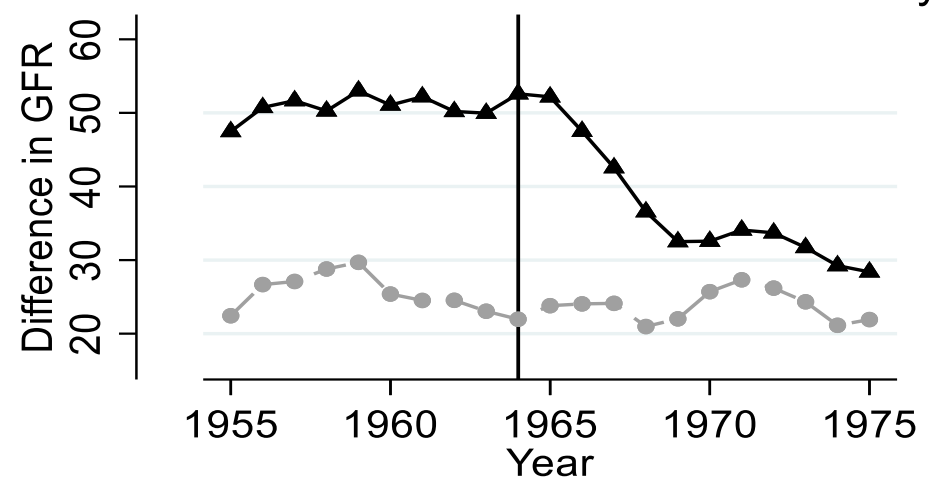

\section{Southern Black - Southern White $\quad--e_{--}^{-}$Northern Black - Northern White}

Notes: Panel A reproduces the baseline results from Figure 1B for reference. Panel B includes the five "border states" (Delaware, Kentucky, Maryland, Oklahoma and West Virginia) as part of the South. Panel C excludes these five border states entirely. Panel D defines the North as seven "Rust-Belt" states (Illinois, Indiana, Missouri, New York, Ohio, and Pennsylvania). 


\section{Figure A2: State Level Results}
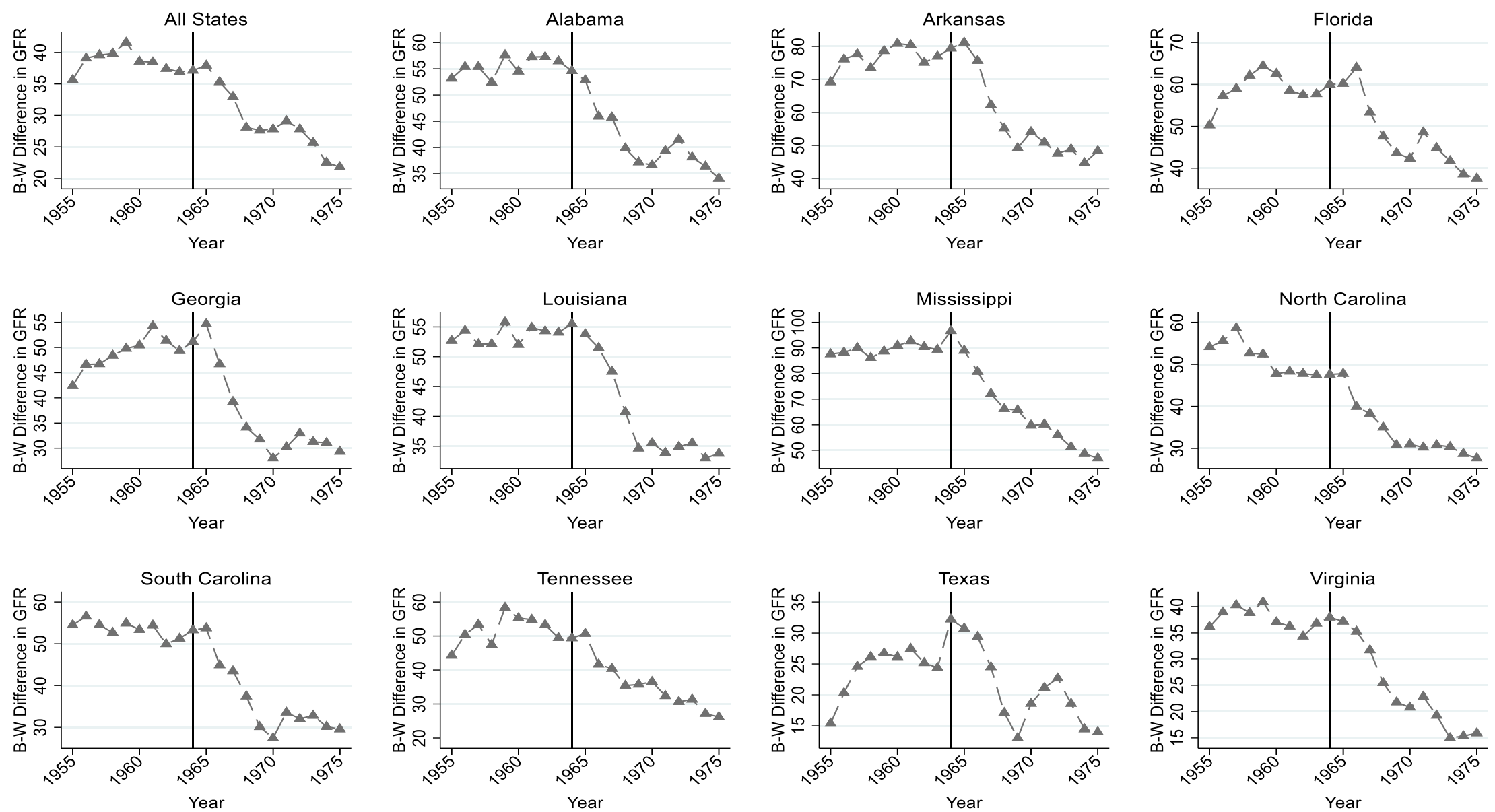

Notes: Figure displays black-white difference in the General Fertility Rate by year in the specified state. Note that the scale of the vertical axis differs by state. 


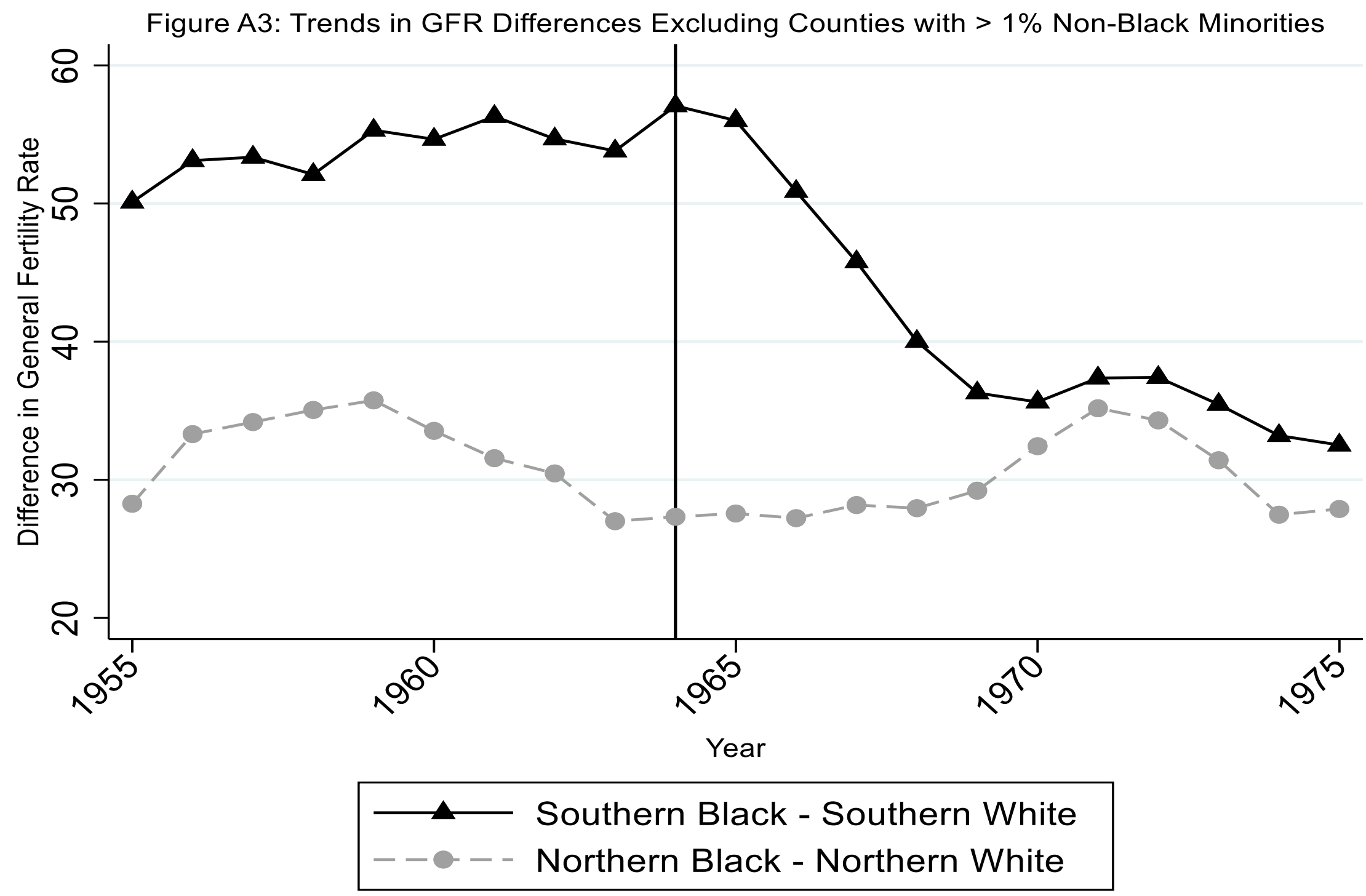

Notes: This figure replicates Figure 1B of the main paper, but excludes counties where African Americans constituted less than 99\% of the non-white population. 
Figure A4: Triple Difference Estimates
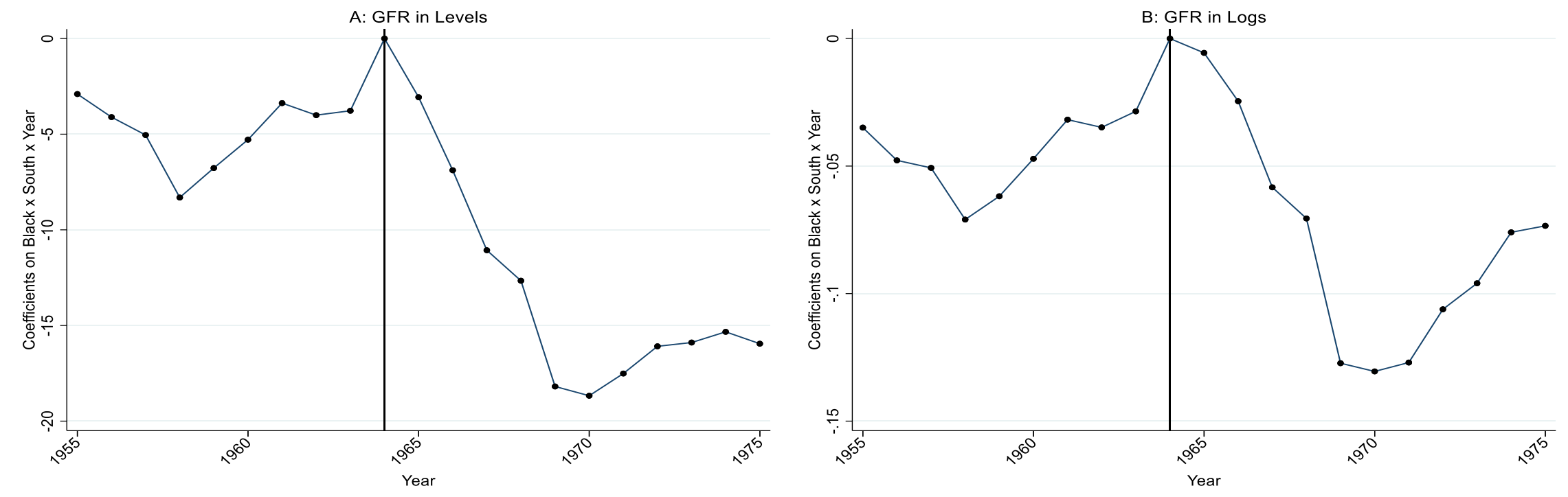

Notes: Figures plot coefficients on the triple-interaction of year dummies with black and South indicators, which estimate the fertility rate of southern blacks relative to the other groups in each year, with 1964 serving as the reference year. See Appendix A for full estimating equation. 
Figure A5: Migration Robustness
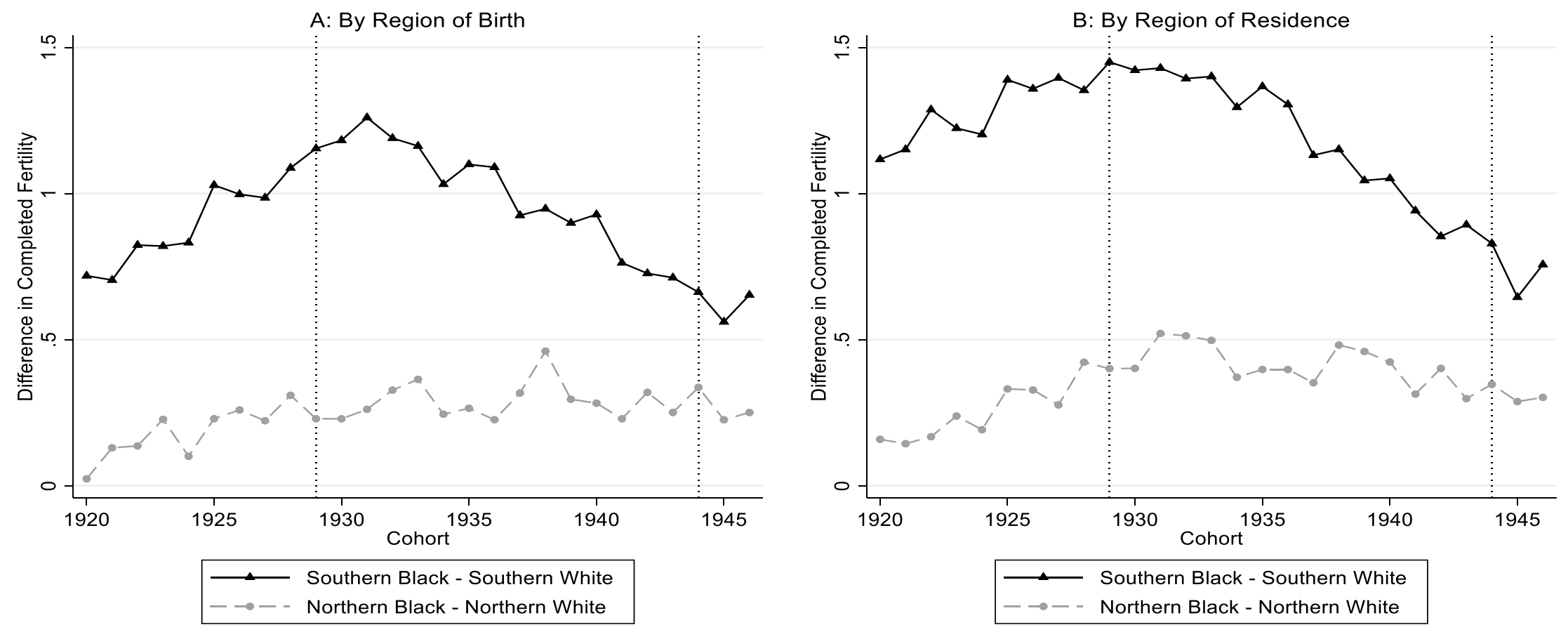

Notes: Figure displays trends in black-white differences in the mean number of children ever born among female Census respondents ages 44-70, disaggregated by region, similar to Figure 3A of the main paper. Panel A defines region using state of birth, while Panel B defines region using state of residence at the time of Census enumeration. 


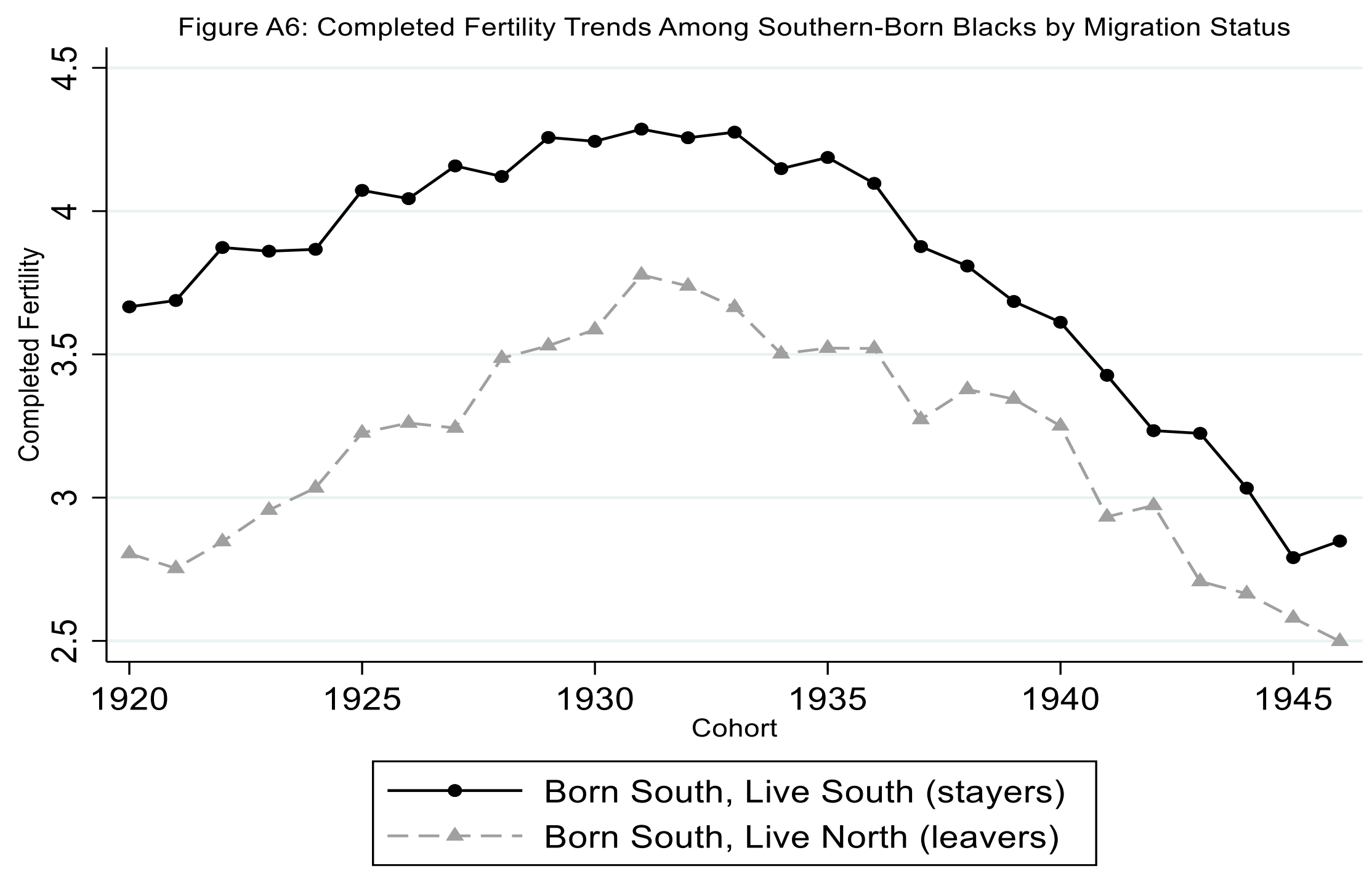

Notes: Figure displays completed fertility trends among southern-born black women, disaggregated by region of residence at the time of Census enumeration. 


\section{Figure A7: CPS Replication of Completed Fertility Trends}

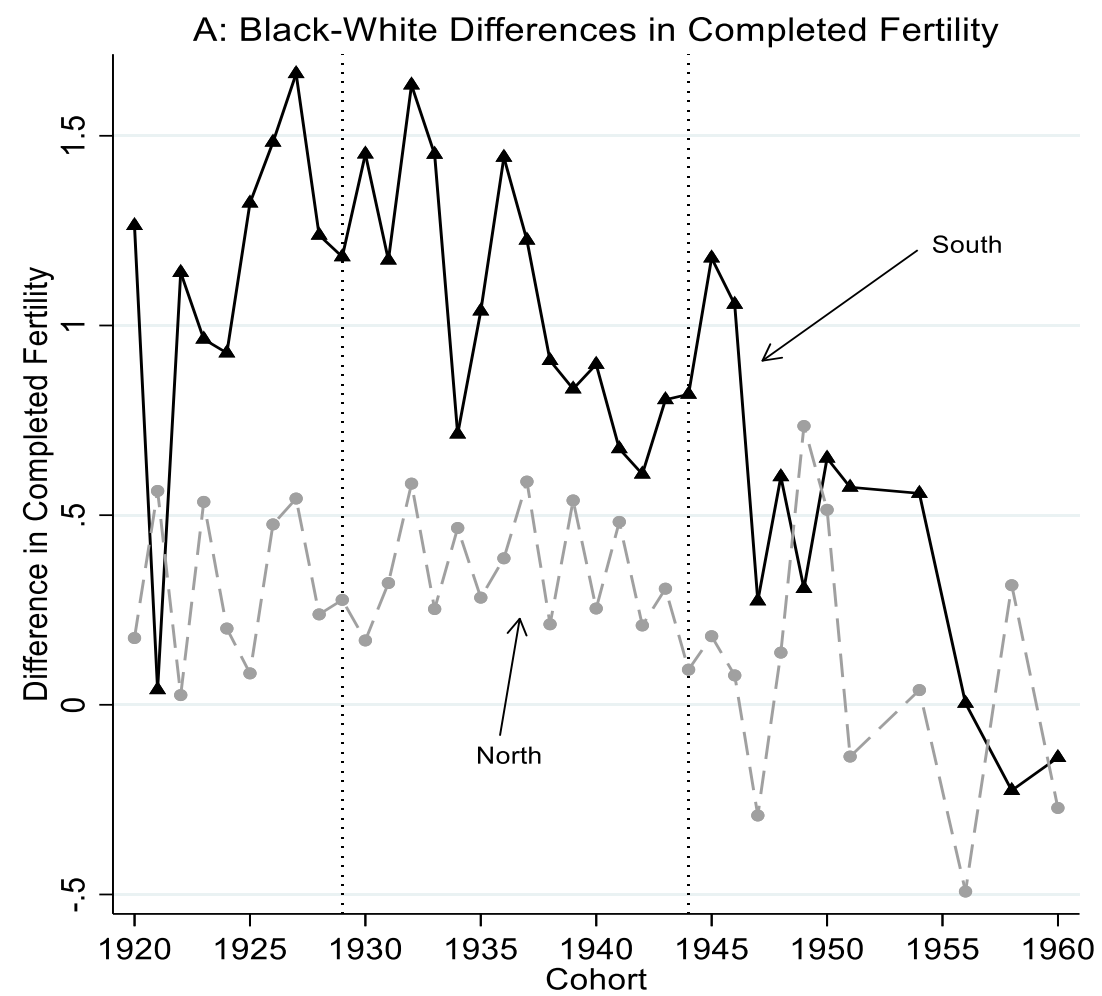

B: Changes in Completed Fertility Distributions
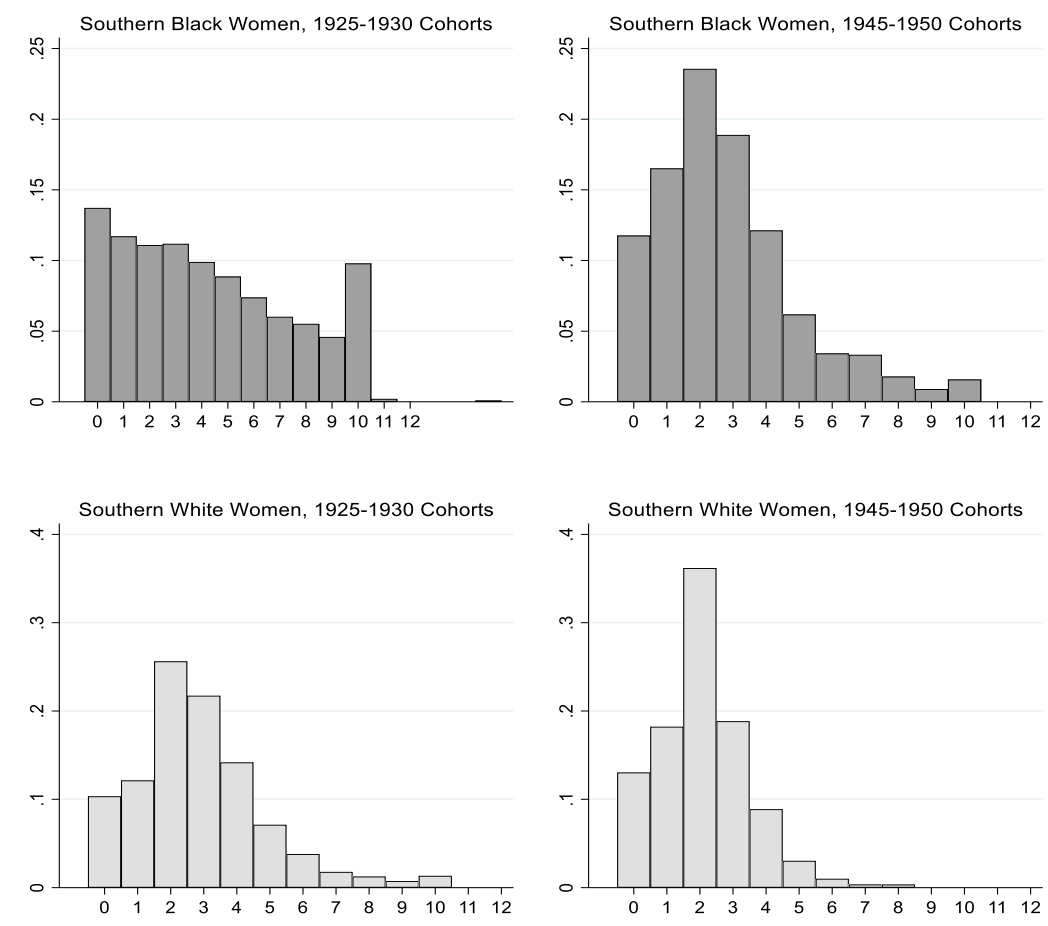

Notes: Figure is identical to Figure 3 of the main paper, but uses CPS June Fertility Suppliments rather than Decennial Census data. Specifically, Panel A displays trends in black-white differences in the mean number of children ever born among female CPS respondents ages 44-70, disaggregated by region. Panel B displays histograms of children ever born among women from the indicated race, region and cohorts. 
Figure A8: Completed Fertility Triple-Difference Results

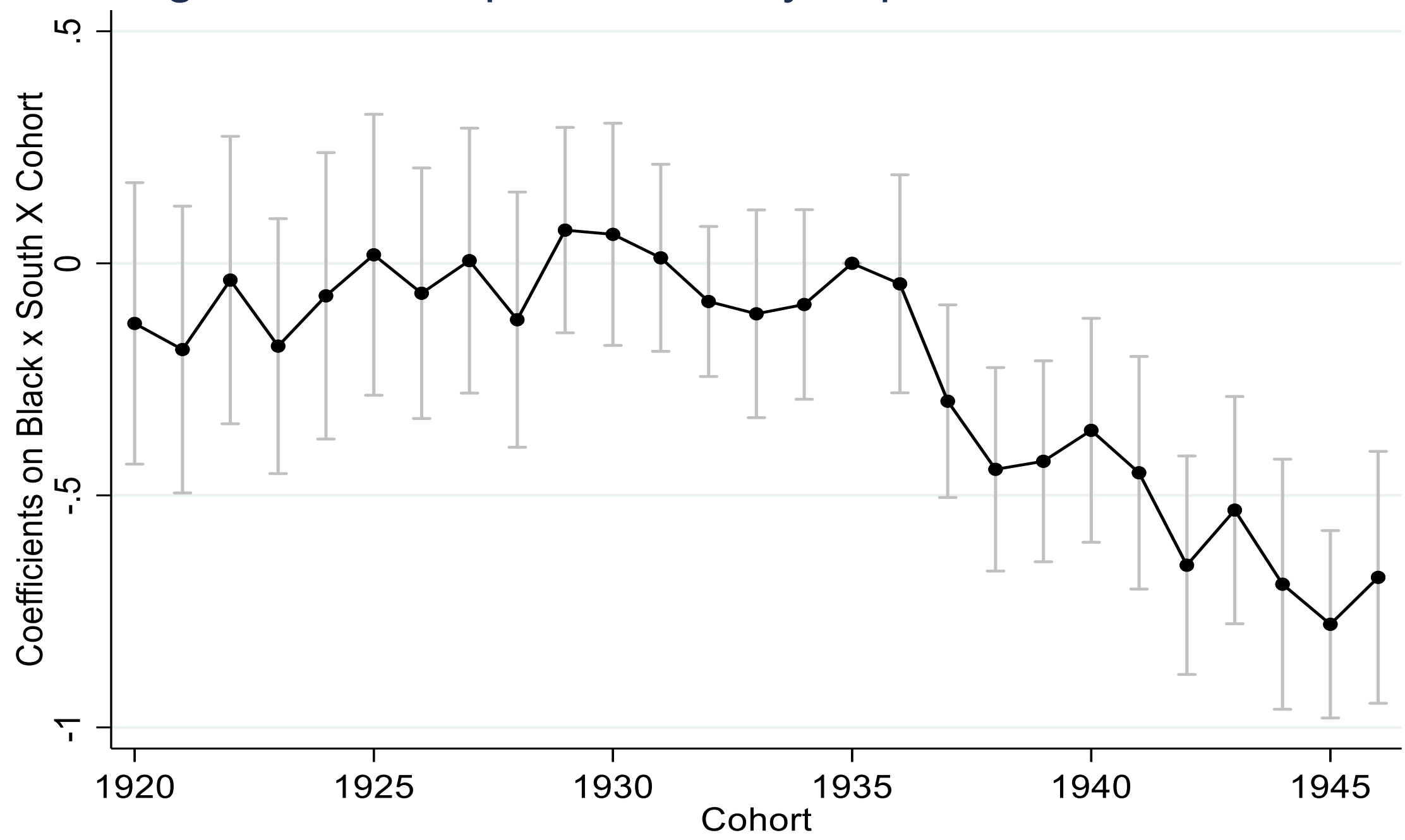

Notes: Figure plots coefficients on the triple-interaction of cohort dummies with black and South indicators, which estimate the average completed fertility of southern blacks relative to the other groups in each cohort, with 1935 serving as the reference year. See Appendix B for full estimating equation. $90 \%$ confidence intervals, calculated with standard errors clustered at the state level, are shows in grey. 
Table A1: GFR Triple-Difference Models

\begin{tabular}{|c|c|c|}
\hline & GFR & Log GFR \\
\hline Black & 25.4 & 0.228 \\
\hline South & -0.9 & -0.009 \\
\hline Black $\times$ South & 27.2 & 0.201 \\
\hline Y1955 & 11.8 & 0.113 \\
\hline Y1956 & 14.3 & 0.135 \\
\hline Y1957 & 16.8 & 0.157 \\
\hline Y1958 & 14.7 & 0.138 \\
\hline Y1959 & 14.9 & 0.140 \\
\hline Y1960 & 13.3 & 0.126 \\
\hline Y1961 & 11.9 & 0.113 \\
\hline Y1962 & 7.4 & 0.072 \\
\hline Y1963 & 3.9 & 0.038 \\
\hline Y1965 & -8.0 & -0.084 \\
\hline Y1966 & -12.9 & -0.139 \\
\hline Y1967 & -16.3 & -0.180 \\
\hline Y1968 & -18.0 & -0.197 \\
\hline Y1969 & -17.3 & -0.188 \\
\hline Y1970 & -16.1 & -0.172 \\
\hline Y1971 & -22.8 & -0.256 \\
\hline Y1972 & -31.1 & -0.371 \\
\hline Y1973 & -35.1 & -0.430 \\
\hline Y1974 & -35.3 & -0.433 \\
\hline Y1975 & -36.8 & -0.456 \\
\hline Black $\times$ Y1955 & -2.2 & -0.038 \\
\hline Black × Y1956 & 2.3 & -0.010 \\
\hline Black $\times$ Y1957 & 4.1 & -0.001 \\
\hline Black × Y1958 & 6.0 & 0.015 \\
\hline Black $\times$ Y1959 & 7.2 & 0.023 \\
\hline Black $\times$ Y1960 & 3.8 & 0.002 \\
\hline Black × Y1961 & 3.0 & -0.000 \\
\hline Black $\times$ Y1962 & 1.6 & -0.002 \\
\hline Black $\times$ Y1963 & 1.1 & 0.001 \\
\hline Black $\times$ Y1965 & 2.7 & 0.040 \\
\hline Black $\times$ Y1966 & 1.8 & 0.046 \\
\hline Black × Y1967 & 1.0 & 0.049 \\
\hline Black $\times$ Y1968 & -0.1 & 0.012 \\
\hline Black × Y1969 & 1.4 & 0.024 \\
\hline Black × Y1970 & 2.5 & 0.025 \\
\hline Black $\times$ Y1971 & 3.3 & 0.048 \\
\hline Black $\times$ Y1972 & 1.6 & 0.057 \\
\hline Black $\times$ Y1973 & -0.6 & 0.047 \\
\hline Black $\times$ Y1974 & -3.6 & 0.011 \\
\hline Black $\times$ Y1975 & -3.2 & 0.013 \\
\hline South $\times$ Y1955 & 1.1 & 0.011 \\
\hline
\end{tabular}




\begin{tabular}{|c|c|c|}
\hline South $\times$ Y1956 & 0.4 & 0.004 \\
\hline South $\times$ Y1957 & -2.1 & -0.018 \\
\hline South $\times$ Y1958 & -1.8 & -0.015 \\
\hline South $\times$ Y1959 & -2.1 & -0.017 \\
\hline South $\times$ Y1960 & -2.5 & -0.022 \\
\hline South $\times$ Y1961 & -2.9 & -0.025 \\
\hline South $\times$ Y1962 & -1.0 & -0.009 \\
\hline South $\times$ Y1963 & -1.0 & -0.009 \\
\hline South $\times$ Y1965 & -1.7 & -0.020 \\
\hline South $\times$ Y1966 & -1.8 & -0.023 \\
\hline South $\times$ Y1967 & -0.2 & -0.005 \\
\hline South $\times$ Y1968 & 1.5 & 0.013 \\
\hline South $\times$ Y1969 & 3.6 & 0.039 \\
\hline South $\times$ Y1970 & 3.0 & 0.031 \\
\hline South $\times$ Y1971 & 5.8 & 0.068 \\
\hline South $\times$ Y1972 & 5.7 & 0.073 \\
\hline South $\times$ Y1973 & 5.4 & 0.072 \\
\hline South $\times$ Y1974 & 3.5 & 0.045 \\
\hline South $\times$ Y1975 & 2.1 & 0.023 \\
\hline Black $\times$ South $\times$ Y1955 & -2.9 & -0.035 \\
\hline Black $\times$ South $\times$ Y1956 & -4.1 & -0.048 \\
\hline Black $\times$ South $\times$ Y1957 & -5.0 & -0.051 \\
\hline Black $\times$ South $\times$ Y1958 & -8.3 & -0.071 \\
\hline Black $\times$ South $\times$ Y1959 & -6.8 & -0.062 \\
\hline Black $\times$ South $\times$ Y1960 & -5.3 & -0.047 \\
\hline Black $\times$ South $\times$ Y1961 & -3.4 & -0.032 \\
\hline Black $\times$ South $\times$ Y1962 & -4.0 & -0.035 \\
\hline Black $\times$ South $\times$ Y1963 & -3.8 & -0.029 \\
\hline Black $\times$ South $\times$ Y1965 & -3.1 & -0.006 \\
\hline Black $\times$ South $\times$ Y1966 & -6.9 & -0.025 \\
\hline Black $\times$ South $\times$ Y1967 & -11.1 & -0.058 \\
\hline Black $\times$ South $\times$ Y1968 & -15.7 & -0.071 \\
\hline Black $\times$ South $\times$ Y1969 & -20.8 & -0.127 \\
\hline Black $\times$ South $\times$ Y1970 & -21.8 & -0.130 \\
\hline Black $\times$ South $\times$ Y1971 & -21.2 & -0.127 \\
\hline Black $\times$ South $\times$ Y1972 & -19.8 & -0.106 \\
\hline Black $\times$ South $\times$ Y1973 & -19.6 & -0.096 \\
\hline Black $\times$ South $\times$ Y1974 & -18.9 & -0.076 \\
\hline Black $\times$ South $\times$ Y1975 & -19.9 & -0.073 \\
\hline Constant & 99.0 & 4.596 \\
\hline Observations & 84 & 84 \\
\hline
\end{tabular}


Table A2: Completed Fertility Triple-Difference Models

\begin{tabular}{|c|c|}
\hline & Children Ever Born \\
\hline \multirow[t]{2}{*}{ Black } & 0.211 \\
\hline & $(0.130)$ \\
\hline \multirow{2}{*}{ South } & $-0.237 * * *$ \\
\hline & $(0.064)$ \\
\hline \multirow[t]{2}{*}{ Black $\times$ South } & $1.218^{* * *}$ \\
\hline & $(0.167)$ \\
\hline \multirow[t]{2}{*}{ C1920 } & $-0.494 * * *$ \\
\hline & $(0.020)$ \\
\hline \multirow[t]{2}{*}{ C1921 } & $-0.441 * * *$ \\
\hline & $(0.018)$ \\
\hline \multirow[t]{2}{*}{ C1922 } & $-0.394 * * *$ \\
\hline & $(0.015)$ \\
\hline \multirow[t]{2}{*}{ C1923 } & $-0.323^{* * *}$ \\
\hline & $(0.013)$ \\
\hline \multirow[t]{2}{*}{ C1924 } & $-0.279 * * *$ \\
\hline & $(0.019)$ \\
\hline \multirow[t]{2}{*}{ C1925 } & $-0.252^{* * *}$ \\
\hline & $(0.021)$ \\
\hline \multirow[t]{2}{*}{ C1926 } & $-0.183^{* * *}$ \\
\hline & $(0.018)$ \\
\hline \multirow[t]{2}{*}{ C1927 } & $-0.127 * * *$ \\
\hline & $(0.012)$ \\
\hline \multirow[t]{2}{*}{ C1928 } & $-0.059 * * *$ \\
\hline & $(0.018)$ \\
\hline \multirow[t]{2}{*}{ C1929 } & $-0.040 * * *$ \\
\hline & $(0.013)$ \\
\hline \multirow[t]{2}{*}{ C1930 } & -0.003 \\
\hline & $(0.018)$ \\
\hline \multirow[t]{2}{*}{ C1932 } & $0.050^{* * *}$ \\
\hline & $(0.011)$ \\
\hline \multirow[t]{2}{*}{ C1933 } & $0.042^{* * *}$ \\
\hline & $(0.014)$ \\
\hline \multirow[t]{2}{*}{ C1934 } & 0.010 \\
\hline & $(0.013)$ \\
\hline \multirow[t]{2}{*}{ C1936 } & $-0.054 * * *$ \\
\hline & $(0.014)$ \\
\hline \multirow[t]{2}{*}{ C1937 } & $-0.137 * * *$ \\
\hline & $(0.013)$ \\
\hline \multirow[t]{2}{*}{ C1938 } & $-0.188^{* * *}$ \\
\hline & $(0.016)$ \\
\hline \multirow[t]{2}{*}{ C1939 } & $-0.257 * * *$ \\
\hline & $(0.013)$ \\
\hline \multirow[t]{2}{*}{ C1940 } & $-0.337 * * *$ \\
\hline & $(0.018)$ \\
\hline
\end{tabular}




\begin{tabular}{|c|c|}
\hline C1941 & $\begin{array}{c}-0.460^{* * *} \\
(0.018)\end{array}$ \\
\hline C1942 & $\begin{array}{c}-0.540^{* * *} \\
(0.021)\end{array}$ \\
\hline C1943 & $\begin{array}{c}-0.645^{* * *} \\
(0.018)\end{array}$ \\
\hline C1944 & $\begin{array}{c}-0.738^{* * *} \\
(0.027)\end{array}$ \\
\hline C1945 & $\begin{array}{c}-0.811 \text { *** } \\
(0.021)\end{array}$ \\
\hline C1946 & $\begin{array}{c}-0.897 * * * \\
(0.021)\end{array}$ \\
\hline Black $\times$ C1920 & $\begin{array}{c}-0.227^{*} \\
(0.135)\end{array}$ \\
\hline Black $\times$ C1921 & $\begin{array}{l}-0.133 \\
(0.121)\end{array}$ \\
\hline Black $\times$ C1922 & $\begin{array}{l}-0.127 \\
(0.101)\end{array}$ \\
\hline Black $\times$ C1923 & $\begin{array}{l}-0.022 \\
(0.112)\end{array}$ \\
\hline Black $\times$ C1924 & $\begin{array}{l}-0.147 \\
(0.136)\end{array}$ \\
\hline Black $\times$ C1925 & $\begin{array}{l}-0.041 \\
(0.136)\end{array}$ \\
\hline Black $\times$ C1926 & $\begin{array}{l}-0.018 \\
(0.116)\end{array}$ \\
\hline Black $\times$ C1927 & $\begin{array}{l}-0.043 \\
(0.109)\end{array}$ \\
\hline Black $\times$ C1928 & $\begin{array}{c}0.069 \\
(0.111)\end{array}$ \\
\hline Black $\times$ C1929 & $\begin{array}{l}-0.019 \\
(0.070)\end{array}$ \\
\hline Black $\times$ C1930 & $\begin{array}{l}-0.016 \\
(0.119)\end{array}$ \\
\hline Black $\times$ C1931 & $\begin{array}{c}0.067 \\
(0.090)\end{array}$ \\
\hline Black $\times$ C1932 & $\begin{array}{c}0.089 \\
(0.067)\end{array}$ \\
\hline Black $\times$ C1933 & $\begin{array}{c}0.133 \\
(0.098)\end{array}$ \\
\hline Black $\times$ C1934 & $\begin{array}{l}-0.004 \\
(0.093)\end{array}$ \\
\hline Black $\times$ C1936 & $\begin{array}{l}-0.038 \\
(0.098)\end{array}$ \\
\hline Black $\times$ C1937 & $\begin{array}{c}0.078 \\
(0.071)\end{array}$ \\
\hline Black $\times$ C1938 & 0.174 \\
\hline
\end{tabular}




\begin{tabular}{|c|c|}
\hline Black $\times$ C1939 & $\begin{array}{c}0.079 \\
(0.094)\end{array}$ \\
\hline Black × C1940 & $\begin{array}{c}0.017 \\
(0.099)\end{array}$ \\
\hline Black × C1941 & $\begin{array}{l}-0.000 \\
(0.100)\end{array}$ \\
\hline Black × C1942 & $\begin{array}{c}0.083 \\
(0.128)\end{array}$ \\
\hline Black $\times$ C1943 & $\begin{array}{c}0.029 \\
(0.113)\end{array}$ \\
\hline Black × C1944 & $\begin{array}{c}0.080 \\
(0.128)\end{array}$ \\
\hline Black $\times$ C1945 & $\begin{array}{l}-0.030 \\
(0.093)\end{array}$ \\
\hline Black $\times$ C1946 & $\begin{array}{c}0.021 \\
(0.129)\end{array}$ \\
\hline South $\times$ C1920 & $\begin{array}{c}0.330^{* * *} \\
(0.059)\end{array}$ \\
\hline South $\times$ C1921 & $\begin{array}{c}0.261 * * * \\
(0.053)\end{array}$ \\
\hline South $\times$ C1922 & $\begin{array}{c}0.242^{* * *} \\
(0.048)\end{array}$ \\
\hline South $\times$ C1923 & $\begin{array}{c}0.197 * * * \\
(0.050)\end{array}$ \\
\hline South $\times$ C1924 & $\begin{array}{c}0.175^{* * *} \\
(0.047)\end{array}$ \\
\hline South $\times$ C1925 & $\begin{array}{c}0.159 * * * \\
(0.042)\end{array}$ \\
\hline South $\times$ C1926 & $\begin{array}{c}0.122^{* * *} \\
(0.042)\end{array}$ \\
\hline South $\times$ C1927 & $\begin{array}{c}0.135^{* * *} \\
(0.031)\end{array}$ \\
\hline South $\times$ C1928 & $\begin{array}{c}0.045 \\
(0.036)\end{array}$ \\
\hline South $\times$ C1929 & $\begin{array}{l}0.057 * \\
(0.033)\end{array}$ \\
\hline South $\times$ C1930 & $\begin{array}{c}0.013 \\
(0.028)\end{array}$ \\
\hline South $\times$ C1931 & $\begin{array}{c}0.020 \\
(0.026)\end{array}$ \\
\hline South $\times$ C1932 & $\begin{array}{c}0.013 \\
(0.022)\end{array}$ \\
\hline South $\times$ C1933 & $\begin{array}{c}0.022 \\
(0.027)\end{array}$ \\
\hline South $\times$ C1934 & $\begin{array}{l}0.044 * \\
(0.024)\end{array}$ \\
\hline
\end{tabular}




\begin{tabular}{|c|c|}
\hline South $\times$ C1936 & $\begin{array}{l}0.045^{*} \\
(0.024)\end{array}$ \\
\hline South $\times$ C1937 & $\begin{array}{c}0.045 \\
(0.032)\end{array}$ \\
\hline South $\times$ C1938 & $\begin{array}{c}0.079 * * \\
(0.031)\end{array}$ \\
\hline South $\times$ C1939 & $\begin{array}{c}0.102^{* * *} \\
(0.031)\end{array}$ \\
\hline South $\times$ C1940 & $\begin{array}{c}0.104 * * * \\
(0.026)\end{array}$ \\
\hline South $\times$ C1941 & $\begin{array}{c}0.151 * * * \\
(0.041)\end{array}$ \\
\hline South $\times$ C1942 & $\begin{array}{c}0.154 * * * \\
(0.034)\end{array}$ \\
\hline South $\times$ C1943 & $\begin{array}{c}0.184 * * * \\
(0.033)\end{array}$ \\
\hline South $\times$ C1944 & $\begin{array}{c}0.195^{* * *} \\
(0.035)\end{array}$ \\
\hline South $\times$ C1945 & $\begin{array}{c}0.223^{* * *} \\
(0.042)\end{array}$ \\
\hline South $\times$ C1946 & $\begin{array}{c}0.213^{* * *} \\
(0.038)\end{array}$ \\
\hline Black $\times$ South $\times$ C1920 & $\begin{array}{l}-0.129 \\
(0.182)\end{array}$ \\
\hline Black $\times$ South $\times$ C1921 & $\begin{array}{l}-0.186 \\
(0.185)\end{array}$ \\
\hline Black $\times$ South $\times$ C1922 & $\begin{array}{l}-0.036 \\
(0.185)\end{array}$ \\
\hline Black $\times$ South $\times$ C1923 & $\begin{array}{l}-0.178 \\
(0.164)\end{array}$ \\
\hline Black $\times$ South $\times$ C1924 & $\begin{array}{l}-0.070 \\
(0.185)\end{array}$ \\
\hline Black $\times$ South $\times$ C1925 & $\begin{array}{c}0.018 \\
(0.181)\end{array}$ \\
\hline Black $\times$ South $\times$ C1926 & $\begin{array}{l}-0.064 \\
(0.162)\end{array}$ \\
\hline Black $\times$ South $\times$ C1927 & $\begin{array}{c}0.006 \\
(0.171)\end{array}$ \\
\hline Black $\times$ South $\times$ C1928 & $\begin{array}{l}-0.121 \\
(0.165)\end{array}$ \\
\hline Black $\times$ South $\times$ C1929 & $\begin{array}{c}0.072 \\
(0.133)\end{array}$ \\
\hline Black $\times$ South $\times$ C1930 & $\begin{array}{c}0.062 \\
(0.143)\end{array}$ \\
\hline Black $\times$ South $\times$ C1931 & $\begin{array}{c}0.012 \\
(0.121)\end{array}$ \\
\hline Black $\times$ South $\times$ C1932 & -0.082 \\
\hline
\end{tabular}


Black $\times$ South $\times$ C1933 -0.109

$(0.134)$

Black $\times$ South $\times$ C1934 $\quad-0.089$

$(0.122)$

Black $\times$ South $\times$ C1936 -0.044

$(0.141)$

Black $\times$ South $\times$ C1937 $\quad-0.297 * *$

$(0.124)$

Black $\times$ South $\times$ C1938 $\quad-0.444 * * *$

Black $\times$ South $\times$ C1939 $\quad-0.427 * * *$

Black $\times$ South $\times$ C1940 $-0.360^{* *}$

$(0.144)$

Black $\times$ South $\times$ C1941 $\quad-0.451 * * *$

Black $\times$ South $\times$ C1942 $-0.650^{* * *}$

$(0.141)$

Black $\times$ South $\times$ C1943 $\quad-0.532^{* * *}$

$(0.147)$

Black $\times$ South $\times$ C1944 $\quad-0.691 * * *$

$(0.161)$

Black $\times$ South $\times$ C1945 $\quad-0.778^{* * *}$

$(0.121)$

Black $\times$ South $\times$ C1946 $-0.677 * * *$

$(0.163)$

Constant

$2.996^{* * *}$

$(0.054)$

Observations

$2,659,501$

R-Squared

0.031

Notes: Sample consists of female black and white respondents to the 1960 and 1970 Census who were ages 44-70 at the time of enumeration. Inter-regional migrants are excluded. Dependent variable is the total number of children ever born. See Appendix B for full estimating equation. Standard errors, clustered by state, are reported in parentheses. ${ }^{*}, * *$ and $* * *$ denote statistical significance at the $10 \%, 5 \%$ and $1 \%$ levels, respectively. 
Table A3: Vital Statistics vs. Census Based Fertility Rate Estimates

\begin{tabular}{|c|c|c|c|c|c|c|}
\hline & (1) & (2) & (3) & (4) & (5) & (6) \\
\hline & \multicolumn{3}{|c|}{ Vital Statistics } & \multicolumn{3}{|c|}{ Census Household Records } \\
\hline & 1960 & 1970 & |Change & 1960 & 1970 & |Change \\
\hline Southern Black & 160 & 118 & 41 & 126 & 86 & 40 \\
\hline Southern White & 109 & 85 & 24 & 102 & 75 & 27 \\
\hline Northern Black & 141 & 107 & 34 & 113 & 82 & 31 \\
\hline Northern White & 112 & 83 & 29 & 107 & 76 & 31 \\
\hline
\end{tabular}

Notes: Table entries report GFR for the specified population and year. Columns 1-3 use the Vital Statistics sample from the Section 1 of the main paper, while Columns 4-6 use Census sample from Section 2.2 of the main paper.

Table A4: Census Fertility Rate Estimates with IMR Adjustments

\begin{tabular}{|c|c|c|c|c|c|c|}
\hline & (1) & (2) & (3) & (4) & (5) & (6) \\
\hline & \multicolumn{3}{|c|}{ Infant Mortality Rates } & \multicolumn{3}{|c|}{ Census Household Records } \\
\hline & 1960 & 1970 & Change & 1960 & 1970 & |Change \\
\hline Southern Black & 47.2 & 34.1 & 13.0 & 132 & 89 & 43 \\
\hline Southern White & 23.8 & 18.1 & 5.7 & 104 & 76 & 28 \\
\hline Northern Black & 40.4 & 29.8 & 10.6 & 118 & 84 & 33 \\
\hline Northern White & 22.1 & 16.9 & 5.2 & 109 & 77 & 32 \\
\hline
\end{tabular}

Notes: Columns 1-3 report infant mortality rates in the specified population and year, measured as the ratio of deaths occurring before age one to the total number of live births, multiplied by 1,000. Columns 4-6 use these infant mortality rates to adjust the Census-based GFR estimates from Table A3 by adding the estimated number of infant deaths to the estimated number of total births. 
Table A5: Robustness of Fertility Convergence Decompositions

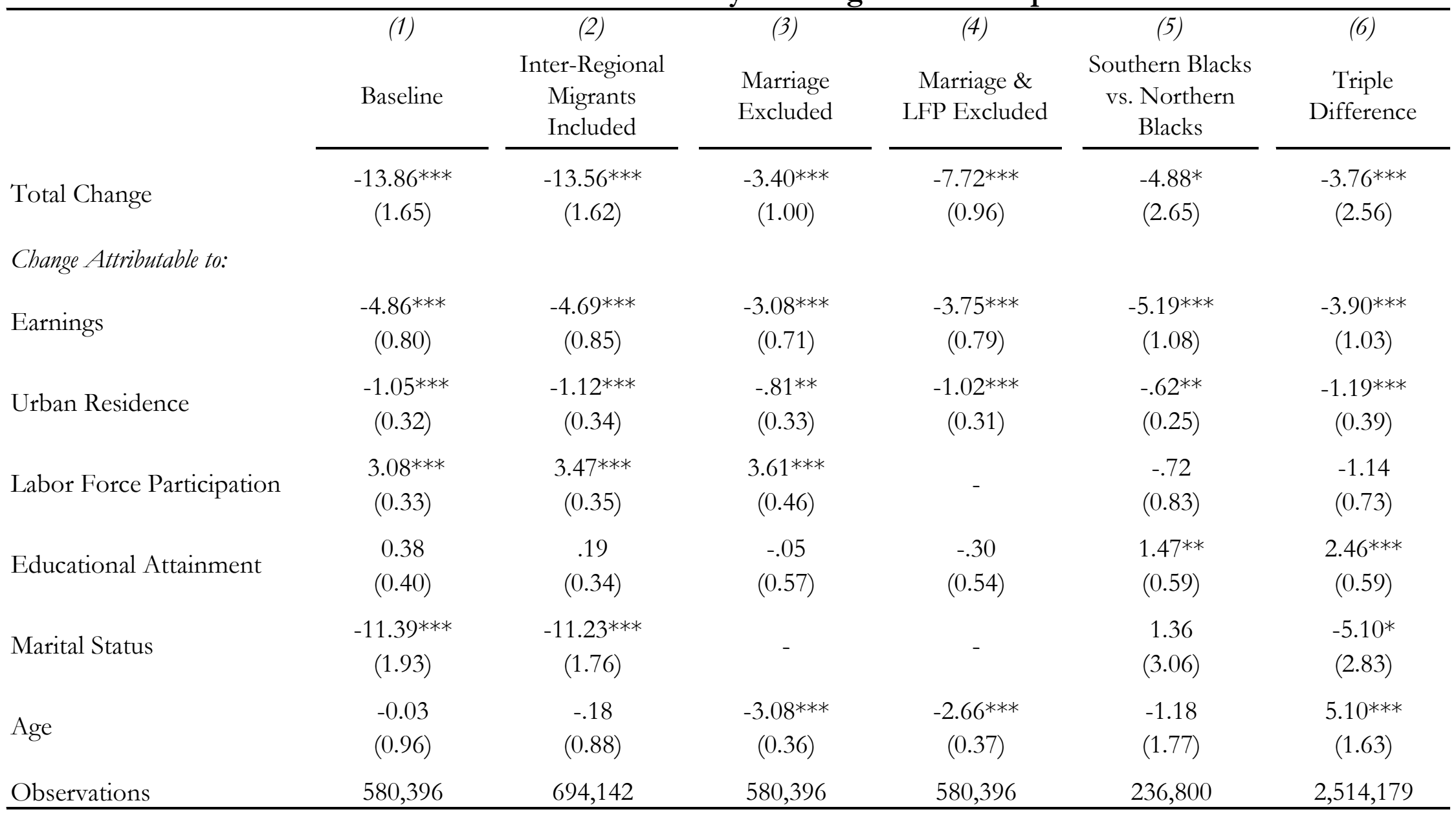

Notes: Baseline results in Column 1 reproduce Column 7 of Table 1 from the main paper. Relative to this baseline specification, Column 2 includes individuals who were born in the North but were residing in the South at the time of enumeration; Column 3 excludes marital status measures from the decomposition; Column 4 excludes both marital status and labor force participation measures from the decomposition; Column 5 uses the sample of African Americans in both regions, excludes southern whites from the sample, and performs the decomposition using the interaction of a 1970 indicator and a South indicator as the independent variable of interest; Column 6 pools observations from both races and both regions and performs the decomposition using the three way interaction of a 1970 indicator, a black indicator and a South indicator as the independent variable of interest. All standard errors are calculated using the formulas derived by Gelbach (2016) with clustering by state of residence and reported in parentheses. ${ }^{*}, * *$ and ${ }^{* * *}$ denote statistical significance at the $10 \%, 5 \%$ and $1 \%$ levels, respectively. 
Table A6: County-Level Correlates of Fertility Convergence

\begin{tabular}{|c|c|c|c|c|c|c|c|c|c|}
\hline & $\begin{array}{c}(1) \\
\Delta \text { GFR } \\
\text { Gap }\end{array}$ & $\begin{array}{c}(2) \\
\Delta \text { GFR } \\
\text { Gap }\end{array}$ & $\begin{array}{c}(3) \\
\Delta \text { GFR } \\
\text { Gap }\end{array}$ & $\begin{array}{c}(4) \\
\Delta \text { GFR } \\
\text { Gap } \\
\end{array}$ & $\begin{array}{c}(5) \\
\Delta \text { GFR } \\
\text { Gap }\end{array}$ & $\begin{array}{c}(6) \\
\Delta \text { GFR } \\
\text { Gap }\end{array}$ & $\begin{array}{c}(7) \\
\Delta \text { GFR } \\
\text { Gap }\end{array}$ & $\begin{array}{c}(8) \\
\Delta \text { GFR } \\
\text { Gap }\end{array}$ & $\begin{array}{c}(9) \\
\Delta \text { GFR } \\
\text { Gap } \\
\end{array}$ \\
\hline$\Delta$ School Integration, 1964-1969 & $\begin{array}{c}0.63 \\
(1.44)\end{array}$ & & & & & & & & $\begin{array}{c}2.59 \\
(1.60)\end{array}$ \\
\hline$\Delta$ Hospital Access, 1964-1969 & & $\begin{array}{c}2.44 \\
(1.36)\end{array}$ & & & & & & & $\begin{array}{l}1.83 \\
(1.36)\end{array}$ \\
\hline $\begin{array}{l}\text { Mean Medicaid Spending Per- } \\
\text { Capita, 1964-1969 }\end{array}$ & & & $\begin{array}{c}2.60 * * * \\
(0.39)\end{array}$ & & & & & & $\begin{array}{c}2.59 * * * \\
(0.38)\end{array}$ \\
\hline $\begin{array}{l}\text { Mean Food Stamp Program } \\
\text { Spending Per-Capita, 1964-1969 }\end{array}$ & & & & $\begin{array}{l}2.21 * * \\
(0.85)\end{array}$ & & & & & $\begin{array}{c}0.98 \\
(0.90)\end{array}$ \\
\hline $\begin{array}{l}\text { Mean Head Start Spending Per- } \\
\text { Four Year Old, 1964-1969 }\end{array}$ & & & & & $\begin{array}{l}0.81 * * \\
(0.32)\end{array}$ & & & & $\begin{array}{l}0.56^{*} \\
(0.29)\end{array}$ \\
\hline $\begin{array}{l}\text { Family Planning Program Ever } \\
\text { Present, 1964-1969 }\end{array}$ & & & & & & $\begin{array}{c}0.29 \\
(2.09)\end{array}$ & & & $\begin{array}{l}0.76 \\
(2.13)\end{array}$ \\
\hline Slave Density, 1860 & & & & & & & $\begin{array}{c}4.32 * * * \\
(1.32)\end{array}$ & & $\begin{array}{l}4.45^{* *} \\
(1.53)\end{array}$ \\
\hline $\begin{array}{l}\text { Lynchings per Black Resident, } \\
\text { 1882-1930 }\end{array}$ & & & & & & & & $\begin{array}{c}2.24^{* *} \\
(0.77)\end{array}$ & $\begin{array}{c}2.00 * * \\
(0.85)\end{array}$ \\
\hline Observations & 675 & 675 & 675 & 675 & 675 & 675 & 675 & 675 & 675 \\
\hline Mean of Ind. Var. & 0.58 & 0.16 & 36.27 & 7.24 & 491.25 & 0.16 & 0.43 & 0.48 & - \\
\hline Standard Deviation of Ind. Var. & 0.37 & 0.16 & 69.81 & 15.29 & 2437.30 & 0.37 & 0.19 & 1.14 & - \\
\hline
\end{tabular}


Table A7: County-Level Correlates of Fertility Convergence, with Controls

\begin{tabular}{|c|c|c|c|c|c|c|c|c|c|}
\hline & $\begin{array}{c}(1) \\
\Delta \text { GFR } \\
\text { Gap }\end{array}$ & $\begin{array}{c}(2) \\
\Delta \text { GFR } \\
\text { Gap }\end{array}$ & $\begin{array}{c}\text { (3) } \\
\Delta \text { GFR } \\
\text { Gap }\end{array}$ & $\begin{array}{c}\text { (4) } \\
\Delta \text { GFR } \\
\text { Gap }\end{array}$ & $\begin{array}{c}(5) \\
\Delta \text { GFR } \\
\text { Gap }\end{array}$ & $\begin{array}{c}\text { (6) } \\
\Delta \text { GFR } \\
\text { Gap }\end{array}$ & $\begin{array}{c}\text { (7) } \\
\Delta \text { GFR } \\
\text { Gap }\end{array}$ & $\begin{array}{c}(8) \\
\Delta \text { GFR } \\
\text { Gap }\end{array}$ & $\begin{array}{c}(9) \\
\Delta \text { GFR } \\
\text { Gap }\end{array}$ \\
\hline$\Delta$ School Integration, 1964-1969 & $\begin{array}{l}0.63 \\
(1.44)\end{array}$ & & & & & & & & $\begin{array}{c}2.16 \\
(1.93)\end{array}$ \\
\hline$\Delta$ Hospital Access, 1964-1969 & & $\begin{array}{c}2.44 \\
(1.36)\end{array}$ & & & & & & & $\begin{array}{c}0.86 \\
(1.40)\end{array}$ \\
\hline $\begin{array}{l}\text { Mean Medicaid Spending Per- } \\
\text { Capita, 1964-1969 }\end{array}$ & & & $\begin{array}{c}2.60 * * * \\
(0.39)\end{array}$ & & & & & & $\begin{array}{c}1.87 * * * \\
(0.44)\end{array}$ \\
\hline $\begin{array}{l}\text { Mean Food Stamp Program } \\
\text { Spending Per-Capita, 1964-1969 }\end{array}$ & & & & $\begin{array}{c}2.21 * * \\
(0.85)\end{array}$ & & & & & $\begin{array}{c}1.46 \\
(1.24)\end{array}$ \\
\hline $\begin{array}{l}\text { Mean Head Start Spending Per- } \\
\text { Four Year Old, 1964-1969 }\end{array}$ & & & & & $\begin{array}{c}0.81 * * \\
(0.32)\end{array}$ & & & & $\begin{array}{c}0.69 * * * \\
(0.19)\end{array}$ \\
\hline $\begin{array}{l}\text { Family Planning Program Ever } \\
\text { Present, 1964-1969 }\end{array}$ & & & & & & $\begin{array}{c}0.29 \\
(2.09)\end{array}$ & & & $\begin{array}{l}1.78 \\
(2.26)\end{array}$ \\
\hline Slave Density, 1860 & & & & & & & $\begin{array}{c}4.32 * * * \\
(1.32)\end{array}$ & & $\begin{array}{l}4.25^{* *} \\
(1.77)\end{array}$ \\
\hline $\begin{array}{l}\text { Lynchings per Black Resident, } \\
\text { 1882-1930 }\end{array}$ & & & & & & & & $\begin{array}{c}2.24 * * \\
(0.77)\end{array}$ & $\begin{array}{c}1.74 \\
(1.26)\end{array}$ \\
\hline Observations & 675 & 675 & 675 & 675 & 675 & 675 & 675 & 675 & 675 \\
\hline Mean of Ind. Var. & 0.58 & 0.16 & 36.27 & 7.24 & 491.25 & 0.16 & 0.43 & 0.48 & - \\
\hline Standard Deviation of Ind. Var. & 0.37 & 0.16 & 69.81 & 15.29 & 2437.30 & 0.37 & 0.19 & 1.14 & - \\
\hline
\end{tabular}

Notes: All specifications include controls each county's total black population, total population of all races, and state fixed-effects. Units of observation are counties in the South. Dependent variable in all specifications is the change in the black-white GFR gap occurring between 1964 and 1969. All independent variables are measured in standardized units (z-scores). See Appendix D for detailed variable descriptions and data sources. Standard errors, clustered by state, are reported in parentheses. $*, * *$ and *** denote statistical significance at the $10 \%, 5 \%$ and $1 \%$ levels, respectively. 